1 The gammaherpesvirus 68 viral cyclin facilitates reactivation by promoting

2 latent gene expression.

3 Brian F Niemeyer ${ }^{1}$, Joy E Gibson², Jennifer N Berger ${ }^{1}$, Lauren M Oko ${ }^{1}$, Eva

$4 \quad$ Medina $^{1}$, Eric T Clambey ${ }^{3}$, Linda F van Dyk ${ }^{1}$

$6 \quad{ }^{1}$ Immunology and Microbiology Department, University of Colorado Denver

7 School of Medicine, Aurora, Colorado, USA, ${ }^{2}$ Department of Pediatrics,

8 University of Colorado School of Medicine, Aurora, Colorado, ${ }^{3}$ Department of

9 Anesthesiology, University of Colorado Anschutz Medical Campus, Aurora,

10 Colorado

11 Address correspondence to: Linda F. van Dyk, University of Colorado School of

12 Medicine, 12800 E. 19th Ave., MS8333, P.O. Box 6511, Aurora, CO, 80045.

13 Phone: (303) 724-4207. Fax: (303) 724-4226. Email:

14 Linda.VanDyk@ucdenver.edu

15 Running Title: viral cyclin is required for optimal gene expression

16 Keywords: gammaherpesvirus, LANA, reactivation, viral cyclin, gene expression

\title{
18 Abstract
}

19 Gammaherpesviruses establish life-long infections within their host and have

20 been shown to be the causative agents of devastating malignancies. Chronic

21 infection within the host is mediated through cycles of transcriptionally quiescent

22 stages of latency with periods of reactivation into more active lytic and productive 
23 infection. The mechanisms that regulate reactivation from latency remain poorly

24 understood. Previously, we defined a critical role for the viral cyclin in promoting

25 reactivation from latency. Disruption of the viral cyclin had no impact on the

26 frequency of cells containing viral genome during latency, yet it remains unclear

27 whether the viral cyclin influences latently infected cells in a qualitative manner.

28 To define the impact of the viral cyclin on latent gene expression, we utilized a

29 viral cyclin deficient variant expressing a LANA-beta-lactamase fusion protein

30 (LANA::Bla), to enumerate both the cellular distribution and frequency of latent

31 gene expression. Disruption of the viral cyclin did not affect the cellular

32 distribution of latently infected cells, but did result in a significant decrease in the

33 frequency of cells that expressed LANA::ßla across multiple tissues and in both

34 immunocompetent and immunodeficient hosts. Strikingly, whereas the cyclin-

35 deficient virus had a reactivation defect in bulk culture, sort purified cyclin-

36 deficient LANA::Bla expressing cells were fully capable of reactivation. These

37 data emphasize that the $\gamma \mathrm{HV} 68$ latent reservoir is comprised of at least two

38 distinct stages of infection characterized by differential latent gene expression,

39 and that a primary function of the viral cyclin is to promote latent gene expression

40 within infected cells in vivo.

\section{AUTHOR SUMMARY}

42 Gammaherpesviruses are ubiquitous viruses with oncogenic potential that establish

43 latency for the life of the host. These viruses can emerge from latency through

44 reactivation, a process that is controlled by the immune system. Control of viral latency

45 and reactivation is thought to be critical to prevent $\gamma \mathrm{HV}$-associated disease. This study

46 focuses on a virally-encoded cyclin that is required for reactivation from latency. By 
47 characterizing how the viral cyclin influences latent infection in pure cell populations, we

48 find that the viral cyclin has a vital role in promoting viral gene expression during latency.

49 This work provides new insight into the function of a virally encoded cyclin in promoting

50 reactivation from latency.

51

52

\section{Introduction}

Gammaherpesviruses $(\gamma \mathrm{HV})$ are a group of lymphotropic viruses within

55 the herpesviridae family, including the human pathogens Epstein-Barr virus

56 (EBV) and Kaposi's sarcoma-associated herpesvirus (KSHV, HHV-8). Infection

57 with these viruses is known to result in development of a wide range of

58 malignancies including Burkitt's lymphoma, Kaposi's sarcoma, nasopharyngeal

59 carcinoma, post-transplant lymphoproliferative disorders, and primary effusion

60 lymphoma [1, 2]. The naturally occurring mouse gammaherpesvirus, $\gamma H V 68$, is

61 closely related to both EBV and $\mathrm{KSHV}$, readily infects laboratory strains of mice,

62 and provides insights into the complex processes of $\gamma \mathrm{HV}$ pathogenesis [3, 4].

$63 \quad$ HHV infection can be characterized by two distinct phases, lytic and

64 latent infection. Lytic infection is a productive form of infection in which the entire

65 suite of viral genes is expressed and the virus actively replicates its genome [5-

66 7]. In this process, new virus is produced and the lytically infected cell dies.

67 Alternatively, the virus may enter a latent state of infection, in which viral gene

68 expression is mostly suppressed and the viral genome is maintained as an

69 episome in the host nucleus [8]. $\gamma \mathrm{HV}$ are able to switch from latent to lytic 
70 infection through a process known as reactivation $[9,10]$. These viruses are able

71 to establish latent infection in many different cell types including dendritic cells,

72 macrophages, and multiple B cell subsets (including memory B cells, plasma

73 cells, B1-a cells, and B1-b B cells) [11-17]. Although several cell types support

74 latent infection, the relative efficiency of these cell types to support reactivation

75 remains unknown. Numerous studies suggest that a primary source of

76 reactivating virus is plasma cells [14, 18-20]. Other studies indicate that in the

77 peritoneal compartment, infected macrophages and/or B1 B cells are major cell

78 types capable of reactivation $[12,13]$.

Many viral and host factors contribute to the control of latent infection

80 and reactivation. KSHV and $\gamma \mathrm{HV} 68$ both encode a conserved viral cyclin ( $\mathrm{v}$ -

81 cyclin), which is homologous to host D-type cyclins [3, 21, 22]. Although EBV

82 does not encode its own cyclin, it expresses viral genes that upregulate host

83 cyclin D2, fulfilling a similar function to the KSHV and $\gamma \mathrm{HV} 68 \mathrm{~V}$-cyclin [23]. Like

84 the host cyclins, the v-cyclin has the ability to interact with host cyclin-dependent

85 kinases (CDKs) and promote cell cycle progression [24, 25]. Unlike conventional

86 host cyclins, the v-cyclin is resistant to inhibition by CDK inhibitors (CKI) [26].

87 Recent work by our group showed that one mechanism by which the v-cyclin

88 promotes reactivation is by antagonizing the host CKI p18Ink4c, in a cell intrinsic

89 manner [27, 28].

90 Although the v-cyclin is required for reactivation from latency, the

91 underlying mechanisms by which it promotes reactivation have yet to be

92 elucidated. Here, we studied how the v-cyclin may influence latent gene 
93 expression in vivo, through the use of recombinant $\gamma \mathrm{HV} 68$ viruses that encode a

94 fusion of the ORF73/LANA latency-associated gene with $\beta$-lactamase, a robust

95 enzymatic reporter gene that can be used to identify individual virally-infected

96 cells [28, 29], referred to as LANA::ßla. By comparing wild-type and cyclin-

97 deficient viruses, we were able to quantify the frequency and cellular distribution

98 of LANA::ßla gene expression during latency. These studies demonstrate that

99 the v-cyclin has a critical role in promoting expression of LANA::ßla at the single-

100 cell level, with no discernable impact on the cellular distribution of infection.

101 Further, we find that the v-cyclin is completely dispensable for reactivation, when

102 reactivation efficiency is tested in LANA::ßla expressing cells. The work detailed

103 here serves to further our understanding of how the virus regulates reactivation.

104 We also highlight an emerging trend in the field of virology where latency is not a

105 uniform state of infection. Rather, some latently infected cells are poised for

106 reactivation, while other infected cells appear to be refractory to reactivation.

\section{Results}

108 A cycKO virus expressing a fusion between LANA and $\beta$ -

109 lactamase is equivalent to wild-type virus in LANA::ßla expression during

110 Iytic infection, but deficient in reactivation. The $\mathrm{v}$-cyclin is required for $\gamma \mathrm{HV} 68$

111 reactivation. Virus lacking $v$-cyclin, cycKO, is equivalent to wild-type virus in

112 replication and establishment of latency, but is selectively defective in

113 reactivation from latency $[30,31]$. Given that some cell types may be more

114 permissive to reactivation from latency than others, we proposed that the cycKO

115 virus may be enriched in, or limited to, a "less permissive" cell type. To address 
116 this, we made use of two previously described enzymatically marked viruses,

117 WT.ßla and cycKO.ßla [28, 29]. These viruses both contain a fusion protein

118 where $\beta$-lactamase is fused to the viral LANA (Fig 1A). This can be used to

119 efficiently identify infected cells by flow cytometry using LANA::ßla expression as

120 a surrogate indicator of virus infection. Fusion of $\beta$-lactamase to LANA does not

121 appear to alter viral replication, establishment of latency, or reactivation from

122 latency [28, 29, 32]. To confirm this reporter system works equivalently for the

123 WT.ßla and cycKO.ßla viruses, we measured the frequency and expression of

124 LANA::ßla after lytic infection of mouse 3T12 fibroblasts. 3T12 cells were infected

125 at an MOI of 10 with WT (unmarked), WT.ßla, or cycKO.ßla virus. At 12 hours

126 post infection (hpi), cells were collected, and stained for $\beta$-lactamase activity

127 using CCF2-AM, a cell-permeable $\beta$-lactamase substrate [28, 29, 32]. CCF2-AM

128 is readily taken up by living cells, causing them to fluoresce at $520 \mathrm{nM}$. If $\beta$ -

129 lactamase is present, indicating viral LANA expression, it then cleaves the

130 substrate causing the cells to gain fluorescence emission at $448 \mathrm{nM}$. As

131 expected, WT.ßla and cycKO.ßla viruses resulted in comparable frequency and

132 expression of LANA::ßla $\left(\beta \mathrm{la}^{+}\right)$following in vitro infection (Fig 1B). We next

133 confirmed that, as reported, the $\beta$-lactamase marker did not alter reactivation

134 phenotypes of either WT or cycKO viruses. C57BL/6 (B6) mice were infected

135 with $1 \times 10^{6}$ PFU of either WT. $\beta$ la or cycKO.ßla virus via intraperitoneal injection

136 (IP). At 42 days post infection (dpi), splenocytes and peritoneal cells were

137 collected and subjected to limiting-dilution reactivation analysis on permissive

138 mouse embryonic fibroblasts (MEFs) as previously described [12, 33]. Briefly, 
139 latently infected splenocytes and peritoneal cells were plated on MEFs. If latent

140 virus reactivates, the resulting virions infect and lyse the MEF monolayer. The

141 number of latently infected cells can then be determined through nonlinear

142 regression analysis. As previously established in comparison of WT and cycKO

143 viruses in absence of the $\beta$ lactamase fusion, the cycKO.ßla virus was severely

144 defective in reactivation from both splenocytes and peritoneal cells (Fig 1C).

145 Taken together, these data support the previous reports that fusion of $\beta$ -

146 lactamase to LANA does not alter the biology of these viruses [28, 29, 32].

147 The cell composition of cycKO. Bla infected mice is not altered

148 compared to WT.ßla infection. To determine if the cycKO virus is preferentially

149 enriched in a particular subset of cells, we infected (B6) mice with $1 \times 10^{6} \mathrm{PFU}$ of

150 either WT.ßla or cycKO.ßla via IP injection. Splenocytes were harvested at $8 \mathrm{dpi}$

151 and $16 \mathrm{dpi}$. Eight dpi is a time point within the acute phase of infection, while 16

152 dpi corresponds to the establishment of latency after acute infection has been

153 resolved [34, 35]. After collection, splenocytes were stained for LANA::Bla, CD19,

$154 \operatorname{lgD}, \mathrm{CD} 38$, and CD44. These markers were used to identify B cells $\left(\mathrm{CD} 19^{+}\right)$,

155 including germinal center $\mathrm{B}$ cells $\left(\mathrm{CD} 19^{+}, \lg \mathrm{D}^{-}, \mathrm{CD}^{-} 8^{-}\right)$or activated $\mathrm{B}$ cells

$156\left(\mathrm{CD}_{19}{ }^{+}, \lg \mathrm{D}^{-}, \mathrm{CD} 44^{+}\right)$. We chose to measure these populations because

157 germinal center B cells represent an important population for $\gamma \mathrm{HV} 68$ to infect and

158 seed memory B cells [36], the primary cell type harboring long-term latent virus,

159 and activating $B$ cells has been show to stimulate reactivation [37]. We

160 determined the composition of infected cells by identifying cells expressing the

161 viral LANA::ßla fusion protein (Fig 2A). We quantified germinal center B cells and 
162 activated $B$ cells by sequentially gating on $C D 19^{+}, \lg D^{-}$, and $C D 38^{-}$or $C D 44^{+}$

163 respectively (Fig $2 \mathrm{~B}$ ). We saw no significant differences in the expression of

164 these markers on total or infected $\left(\beta \mathrm{la}^{+}\right)$splenocytes at 8 dpi during acute

165 infection (Fig 2C) or at 16 dpi during latency (Fig 2D). In agreement with this,

166 there were no differences between WT.ßla or cycKO.ßla virus in the frequency of

$167 \mathrm{Bla}^{+}$cells that were total B cells, germinal center B cells, or activated B cells (Fig

$1682 \mathrm{2E})$. Contrary to our initial prediction, these data suggest that although the

169 cycKO.ßla virus is defective in reactivation there are no appreciable differences

170 in the composition of the infected cells compared to WT.ßla virus. Thus, there

171 must be another explanation for the reactivation defect observed in v-cyclin

172 deficient viruses.

173 CycKO.ßla virus infection results in deficient expression of viral

174 LANA compared to WT. $\beta$ la. Splenocytes, from mice infected as above, were

175 collected at 8 and 16 dpi and analyzed by limiting-dilution nested PCR to

176 measure the frequency of splenocytes harboring viral DNA [12, 33]. We found

177 that there was a minor decrease in the number of cells harboring cycKO.ßla virus

178 at 8 dpi but no significant difference in the number of cells containing $\gamma H$ V68 DNA

179 following infection at $16 \mathrm{dpi}$ (Fig 3A). These data indicate that the reactivation

180 defect in cycKO virus is not due to fewer cells becoming infected, consistent with

181 previously published reports [28, 30]. However, when splenocytes were

182 analyzed for the frequency of LANA::ßla expressing cells, we found a significantly

183 lower frequency of LANA::ß/a ${ }^{+}$cells in mice infected with cycKO. $\beta$ la $(0.06 \%)$

184 compared to wild-type virus infected samples $(0.21 \%)$ at 8 dpi. Further, this trend 
185 continued into latency with $0.03 \%$ of splenocytes at 16 dpi that were LANA:: $\beta l a^{+}$

186 after WT.ßla infection compared to $0.008 \%$ of splenocytes after cycKO.ßla

187 infection (Fig 3B). This difference in frequency corresponded to a decrease in the

188 total number of LANA::ßla ${ }^{+}$splenocytes per mouse after infection with the

189 cycKO.ßla virus (Fig 3C). Considering an equivalent number of cells are viral

190 DNA positive (Fig 3A), this indicates that there is a decrease in the proportion of

191 infected cells that expressed LANA in the absence of v-cyclin. This decreased

192 frequency of LANA::ßla ${ }^{+}$cells that are B cells, germinal center B cells, or memory

193 B cells translated into a sharp decline in the number of LANA::ßla ${ }^{+}$cells in

194 cycKO.ßla infected mice compared to WT.ßla infected mice across multiple

195 subsets (Fig 3D). As WT.ßla and cycKO.ßla viruses had comparable $\beta$-lactamase

196 expression during lytic infection of $3 \mathrm{~T} 12$ cells (Fig 1B), these data indicate that

197 the v-cyclin promotes the frequency of LANA expressing cells during latent

198 infection in vivo.

199 The defect in LANA expression with cycKO.ßla infection is

200 observed regardless of the tissue type. While we consistently observed a

201 decrease in the frequency of cells expressing LANA::ßla after cycKO.ßla

202 infection, it remained possible that this was a tissue-specific phenotype. To

203 address this possibility, mice were infected IP as described above and peritoneal

204 cells were collected at 8 and $16 \mathrm{dpi}$, stained for $\beta$-lactamase, CD19, and CD5.

205 CD19 was used to distinguish between non-B cells and B cells (CD19 $)$ and CD5

206 expression on $\mathrm{CD}_{19}{ }^{+}$cells was used to identify B1-a cells, which are known to

207 harbor latent virus in the peritoneum (Fig 4A) [13, 28]. We saw no significant 
208 difference in the cellular distribution of infection between WT and cycKO viruses

209 (Fig 4B), but a profound decrease in the frequency of LANA:: $\mathrm{Bla}^{+}$cells in

210 peritoneal cells harvested from cycKO.ßla infected mice (Fig 4C). There was a

211 significantly lower frequency of LANA:: $\beta \mathrm{Ia}^{+}$peritoneal cells after cycKO. $\beta l a$

212 infection at both 8 and $16 \mathrm{dpi}$ (Fig 4D). This indicates that the $\mathrm{v}$-cyclin is required

213 for optimal LANA expression in the peritoneum and the spleen, two dominant

214 sites for latency. Finally, to determine whether this effect was dependent on route

215 of infection, we measured the frequency of LANA:: $\beta \mathrm{la}^{+}$cells in the lungs at 8

216 days post-intranasal infection (Supplemental Fig 1). Again, mice infected with

217 cycKO. $\beta l a$ virus had a reduced frequency and number of LANA::ßßla ${ }^{+}$compared

218 to WT.ßla infected mice. These data demonstrate that the v-cyclin is required for

219 optimal LANA expression, regardless of tissue or route of infection.

221 immunodeficient, CD8-deficient mice. The v-cyclin is required for optimal

222 reactivation across both immunocompetent and immunodeficient genetic

223 backgrounds $[30,33,38]$. CD8-deficient $\left(C D 8^{-1}\right)$ mice, which lack CD8 T cells,

224 have a significant increase in the number of latently infected cells relative to B6

225 controls [39]. Despite the overall increase in the number of latently infected cells,

226 the cycKO.ßla virus is still defective in reactivation in these mice [33]. We

227 therefore tested whether the v-cyclin was required to promote LANA expression

228 in $\mathrm{CD}^{-/-}$mice.

CD8-/- mice were infected via IP inoculation with either WT. $\beta$ la or

230 cycKO. $\beta$ la virus. Splenocytes were harvested at $16 \mathrm{dpi}$ and stained for $\beta$ - 
231 lactamase activity, CD19 expression, and IgD and CD38 expression on CD19+

232 cells. We found that, as with B6 mice, there were no differences in cellular

233 distribution of LANA::ßla ${ }^{+}$between WT and cycKO viruses (Fig 5A, 5C).

234 Importantly, the defect in LANA::Bla expression in cycKO infected splenocytes is

235 still maintained, with a 5.6-fold decrease in the frequency of splenocytes that are

$236 \beta l a+$ after cycKO.ßla infection (0.0034\%) compared to WT.ßla infection $(0.019 \%)$

237 (Fig 5B). We also analyzed peritoneal cell infection at 16 dpi. Peritoneal cells

238 from mice infected as above were collected and stained for $\beta$-lactamase activity,

239 CD19, B220, and CD5. The cycKO. Bla defect was also present in the peritoneal

240 compartment, with only $0.054 \%$ of peritoneal cells LANA:: $3 \mathrm{la}^{+}$in cycKO infected

241 samples compared to $0.496 \%$ LANA::Bla ${ }^{+}$cells after WT. $\beta$ la infection (Fig 6A,

242 6B). Interestingly, we detected a modest shift in the peritoneal composition of

243 LANA:: $\beta \mathrm{la}^{+}$cycKO. $\beta l a$ infected cells: $25 \%$ of cycKO. $\beta$ la infected LANA::ßla ${ }^{+}$cells

244 were $\mathrm{CD}_{19}{ }^{+}$compared to $12 \%$ of WT. $\beta$ la infected LANA::Bla ${ }^{+}$cells (Fig $6 \mathrm{C}$ ). This

245 difference mirrors a change in the total frequency of $\mathrm{CD} 19^{+}$cells in the

246 peritoneum after cycKO.ßla infection (Fig 6C). When analyzing the composition

247 of infected B cells by B220 and CD5 expression, the LANA::ßla ${ }^{+}$cells were found

248 in B1-a, B1-b, and B2 cells, with a higher prevalence in B1 populations. Of

249 WT. $\beta$ la infected LANA:: $\beta$ la $^{+}$cells: $4 \%$ were B2 cells, $5 \%$ were B1-a cells, and $8 \%$

250 were B1-b cells. Of the cycKO. $\beta$ la infected LANA::ßla+ cells: $10 \%$ were B2 cells,

$2518 \%$ were B1-a cells, and $10 \%$ were B1-b cells (Fig 6C). Interestingly, we have

252 previously identified a similar trend in p18Ink4c deficient mice, a mouse strain in

253 which there is an overall increase in reactivation [28], similar to the CD8-/- mice. 
255 activity, we isolated WT or cycKO infected peritoneal cells and measured both $\beta$ -

256 lactamase and LANA RNA by qRT-PCR (Fig 6D). Similar to analysis by

257 enzymatic activity, these data demonstrate a difference in latent gene expression

258 at the RNA level between WT and cycKO infected cells at $16 \mathrm{dpi}$. These data

259 indicate that the $\mathrm{v}$-cyclin is required for optimal LANA gene expression in multiple

260 tissues and in both immunocompetent and immunodeficient hosts.

263 cells. The reduced frequency of LANA expressing cells after cycKO.ßla infection

264 in both $\mathrm{B} 6$ and $\mathrm{CD} 8^{-/-}$mice correlates with the reactivation defect of the

265 cycKO.ßla virus observed in these mice. It has also been previously reported that

266 sort purifying LANA::Bla ${ }^{+}$cells can enrich for cells capable of reactivation [29].

267 Based on these observations, we postulated that the defect in reactivation of 268 cycKO viruses may be a direct consequence of the reduced frequency of LANA

269 expressing cells. To this end, we used flow sorting to purify LANA:: $3 \mathrm{la}^{+}$cells from

270 mice infected with either WT.ßla and cycKO.ßla virus and measured reactivation

271 capacity ex vivo. Given the low frequency of $\beta \mathrm{la}^{+}$cells in healthy B6 mice (Fig

$2723 \mathrm{~B}, 4 \mathrm{C}$, and $5 \mathrm{~A}$ ), we sorted LANA::Bla ${ }^{+}$cells from $\mathrm{CD}^{-/-}$mice. CD8-/- mice were

273 infected with WT.ßla or cycKO.ßla virus via IP injection with peritoneal cells

274 harvested at $16 \mathrm{dpi}$, stained for $\beta$-lactamase expression and FACS purified into

275 either LANA::Bla ${ }^{+}$or LANA::Bla- populations (Fig 7A), followed by flow cytometric

276 analysis of sort purity (Fig 7B). For each sort, we recovered $\sim 25,000-100,000$ 
277 WT.ßla infected LANA::ß3la ${ }^{+}$cells, $~ 21,000-24,000$ cycKO.ßla infected LANA::ßla ${ }^{+}$

278 cells, and $\sim 1.5-2 \times 10^{6}$ LANA::ßla cells for each virus. Bulk, LANA::ßla ${ }^{+}$, and

279 LANA::ßla cells were plated by serial dilution on MEF monolayers and assessed

280 for reactivation 21 days post-plating. As expected, in the pre-sorted population

281 the cycKO.ßla virus showed a reactivation defect relative to WT.ßla infected

282 peritoneal cells (Fig 7C). Reactivation in the LANA::ßla- population was extremely

283 low. In contrast to the low frequencies of reactivation present in the LANA::ßla

284 population, LANA::ßla ${ }^{+}$cultures had much higher frequencies of reactivation (Fig

$2857 \mathrm{C})$. Notably, when the number of LANA expressing cells analyzed for

286 reactivation was normalized between WT.ßla and cycKO.ßla infected samples,

287 the cycKO.ßla had equivalent reactivation to WT.ßla virus (Fig 7C). These data

288 directly demonstrate that LANA expressing cells are enriched in their ability to

289 reactivate from latency, and provide direct evidence that a primary function of the

$290 \mathrm{~V}$-cyclin is to promote the frequency of LANA expressing cells during latent

291 infection in vivo. They further indicate that the defect in reactivation observed in

292 bulk cultures from cycKO infected mice can be directly attributed to a reduced

293 frequency of LANA expressing cells in the cycKO infected latent reservoir.

\section{Discussion}

The balance between latency and reactivation is of critical importance in

$297 \gamma \mathrm{HV}$ infection and disease progression. Chronic infection with $\gamma \mathrm{HV}$ through

298 maintenance of latency and reactivation has long been associated with virus-

299 induced malignancies [1]. Here, we find that a primary function of the v-cyclin is 
300 to promote latent gene expression (i.e. LANA), to create a reactivation competent

301 latent reservoir. Our findings suggest that $\gamma \mathrm{HV} 68$ latency is not a uniform state.

302 Indeed, it appears that some latently infected cells are more prone to reactivation

303 while others seem refractory. In the work presented here, we show that LANA

304 expression is a strong correlate with reactivation capacity, while cells that fail to

305 express LANA have limited reactivation potential (Fig 7C). Therefore, we propose

306 a more comprehensive model of gammaherpesvirus reactivation where either the

307 viral cyclin, or potentially host cyclins, promote reactivation by altering the state

308 of the latently infected cell (Fig 8). In this specific instance, expression of v-cyclin

309 increases the pool of LANA expressing latently infected cells, which are more

310 permissive to reactivation from latency (Fig 8).

311 The notion that viral latency is a diverse and complex state of infection

312 was originally defined in EBV infection, in which there are several distinct types

313 of latency [40]. These diverse latency stages are distinguished by variable

314 expression of viral genes in a manner that is mimicked with cyclin-deficient

$315 \gamma \mathrm{HV} 68$ infection. Further, different EBV latency programs are associated with

316 specific clinical outcomes and pathologies [41, 42]. While our findings likely

317 reflect a conserved feature of biology amongst gammaherpesvirus, similar trends

318 can be observed in latent infection across virus families. For example, in HIV

319 infection, virus persists within the host through latency in many cells types,

320 including CD4 T cell subsets and myeloid cells $[43,44]$. Since these reservoirs

321 cannot be cleared by therapeutics or the host immune system, one potential

322 strategy for eradication of the virus is to trigger reactivation, resulting in death of 
323 the cell by the virus or the host immune system [45]. One barrier to this approach

324 is the fact that distinct populations of latently infected cells appeared differentially

325 responsive to reactivation stimuli [46].

326 One important question raised by our findings is how broadly the v-cyclin

327 is required for latent gene expression: is this effect specific to LANA, or does it

328 apply more broadly to additional viral genes (e.g. M2)? In terms of how the v-

329 cyclin is regulating latent gene expression, it is possible that loss of v-cyclin is

330 associated with a defect in epigenetic remodeling, resulting in broad repression

331 of viral gene expression. While the v-cyclin promotes the frequency of LANA

332 expressing cells, it is notable that the LANA expression during latency can occur

333 independent of the v-cyclin. In our previous studies, we have identified two

334 contexts in which reactivation can occur in a v-cyclin independent manner: i)

335 genetic, or physiological, loss of p18Ink4c enables robust reactivation of $\gamma \mathrm{HV} 68$

336 in cycKO infection [27, 28], and ii) host cyclin D3 is capable of fulfilling the role of

337 v-cyclin in driving reactivation in a cycKO background, albeit with a decreased

338 efficiency [47]. Based on these observations, it is possible that cycKO infected

339 cells with LANA expression may reflect cells with either increased cellular D type

340 cyclin expression and/or decreased p18Ink4c expression, allowing both LANA

341 expression and reactivation. Although our data emphasize that the v-cyclin

342 promotes LANA expression and that LANA expressing cells are reactivation

343 competent, it remains to be tested whether the v-cyclin supports additional

344 features for optimal reactivation capacity. 
345 The work described here documents a critical link between v-cyclin and

346 viral LANA expression in reactivation from latency. Further, our findings strongly

347 suggest that the latently infected reservoir is diverse in gene expression and

348 reactivation capacity. These data identify a v-cyclin/LANA axis that is critical for

349 reactivation from latency and emphasize that efforts to manipulate this axis may

350 require a combinatorial approach that targets both v-cyclin dependent and

351 independent processes to effectively disrupt the latent reservoir.

352

\section{$353 \quad$ Methods and Materials}

354 Cell lines and viruses: $3 T 12$ mouse fibroblast cells (ATCC CCL-164)

355 were cultured in 5\% FBS/DMEM with 20 units of penicillin and $20 \mu \mathrm{g}$ of

356 streptomycin per $\mathrm{mL}$ and $4 \mathrm{mM} \mathrm{L-glutamine.} \mathrm{MEFs} \mathrm{were} \mathrm{isolated} \mathrm{as} \mathrm{described}$

357 and cultured in 10\% FBS/DMEM with 20 units of penicillin per $\mathrm{mL}, 20 \mu \mathrm{g}$ of

358 streptomycin per mL, $4 \mathrm{mM} \mathrm{L-glutamine,} \mathrm{and} \mathrm{fungizone} \mathrm{at} 250 \mathrm{ng} / \mathrm{mL}$ [48].

359 Generation of the WT. $\beta$ la and cycKO.ßla viruses has been previously described $360 \quad[28,29,32]$.

$361 \quad$ Mice. C57BL/6 (B6) mice were obtained from the Jackson Laboratory

362 (Stock \# 000664). CD8 $\alpha$-/- mice on the B6 background (CD8-/-) were obtained

363 from the Jackson Laboratory (Stock \# 002665) and have been previously

364 described [39]. CD8-/- mice were bred in house at the University of Colorado

365 Denver Anschutz Medical Campus in accordance with University regulations and

366 Institutional Animal Care and Use Committee. 
Flow cytometry analysis: Spleens were collected and splenocytes were

368 isolated in a single cell suspension after being passed through a 100 micron

369 filter. Splenocytes were then subjected to red blood cell lysis by treatment with

370 red blood cell lysis buffer (Sigma \# R7757) per manufacturer's recommendation.

371 Peritoneal cells were collected with $10 \mathrm{mLs}$ of cold $1 \%$ FBS DMEM. $\beta$-lactamase

372 activity was detected using the LiveBLAzer FRET-BG/Loading Kit with CCF2-AM

373 (ThermoFischer Scientific \# K1025) as previously described [17, 29, 32]. Cell

374 surface antibodies used were CD19-AlexaFluor 700 (clone eBio1D3, eBioscience

375 \# 56-0193-81), CD38-APC (clone 90,eBiosciences \#17-0382-81), IgD-APC-Cy7

376 (clone 11-26c.2a, Biolegend \# 405716), and CD5-APC (clone 53-7.3,

377 eBioscience \# 17-0051-81). Fc blocking antibody 24G2 was used in staining to

378 prevent antibody binding to cellular Fc receptors.

379 Limiting-dilution analysis: Mice were inoculated with either WT. $\beta l a$ or

380 cycKO. $\beta$ la at $1 \times 10^{6} \mathrm{PFU} / \mathrm{mouse}$ via IP injection. After 8 and 16 days, splenocytes

381 and peritoneal cells were collected as above and analyzed by either flow

382 cytometry or plated for reactivation or PCR analysis. By Poisson distribution, the

383 number of cells plated corresponding to $63.2 \%$ of the wells positive is the

384 frequency at which there is at least one reactivating or genome positive cell,

385 respectively.

386 Reactivation analysis. Cells were subjected to serial limiting dilution

387 analysis, and plated on highly permissive MEF monolayers for quantification of

388 virus cytopathic effect as previously described [12, 33]. To control for any 
389 preformed virus, mechanically disrupted peritoneal cells were plated in parallel;

390 no monolayer disruption was observed in disrupted cells.

$391 \quad$ LD-PCR analysis. Cell dilutions were subjected to in-plate DNA isolation

392 and nested-PCR for single copy sensitivity detection of viral gene 50 DNA, with

393 plasmid sensitivity controls included on each plate, as previously described [12,

394 33].

395 Quantitative-PCR analysis: CD8-/- mice were infected with $1 \times 10^{6}$ PFU

396 of either WT.ßla $(n=3)$ or cycKO.ßla $(n=3)$ virus or mock infected $(n=2)$ via IP

397 injection. At 16 dpi, peritoneal cells from individual mice were harvested from

398 each mouse, pelleted at 1,000xg for $10 \mathrm{~min}$, resuspended in RLT buffer

399 containing $\beta$-mercaptoethanol and then frozen at $-80^{\circ} \mathrm{C}$. Cells were then thawed

400 and homogenized via Qiashredder columns and RNA was isolated using the

401 RNeasy Micro Kit. DNA was removed from the samples by treating with Turbo

402 DNase as per the manufacturer's recommendations (ThermoFisher). cDNA was

403 synthesized using Superscript II Reverse Transcriptase (ThermoFisher). Primers

404 for SYBR Green qPCR were designed using Primer3. Primers used were: LANA

405 Forward 5'-ATCAGGGAATGCGAAGACAC, LANA Reverse 5'-

406 GTGCCTGGTACCAAGGGTAA, $\beta$-lactamase Forward 5’-

407 GCTATGTGGCGCGGTATTAT, $\beta$-lactamase Reverse 5'-

408 AAGTTGGCCGCAGTGTTATC. iQ SYBR Green Supermix was used for the 409 qPCR reactions (Bio-Rad) and qPCR was performed with technical triplicates

410 from the peritoneal cell cDNA of each mouse, and run on the QuantStudio 7 Flex 411 instrument. 
FACS sorted reactivation: CD8-/- mice were infected with $1 \times 10^{6}$ PFU of

413 either WT.ßla or cycKO.ßla virus via IP injection. At 16 dpi, peritoneal cells were

414 collected and combined for each virus group. For each virus group, $1 \times 10^{6}$ cells

415 were set aside as "pre-sorted" cells. The remaining cells were stained for $\beta$ -

416 lactamase then washed and resuspended in $2 \%$ FBS in PBS. These cells were

417 then sorted by the Clinical Immunology Flow Core with the University of Colorado

418 Anschutz Medical Campus. Cells were gated as single cells and then sorted into

$419 \beta \mathrm{la}^{+}$or $\beta$ la ${ }^{-}$populations. A small number of LANA::ßla ${ }^{+}$WT. .

420 tested for purity after the sort had concluded. The purity of the LANA::ß3la ${ }^{+}$cells

421 was measured in the WT. $\beta$ la infected samples and found to be $97.3 \%$ pure . A

422 corresponding purity check was not performed for the cycKO.ßla infected

423 samples due to a lower total number of cells recovered. Pre-sorted, LANA::ßla ${ }^{+}$,

424 or LANA::Bla cells were diluted into 10\% FBS in DMEM and plated onto

425 permissive MEFs in a limiting-dilution fashion as previously described [12, 33].

426 Pre-sorted and LANA:: $\beta$ la cells were plated at starting concentrations of $2 \times 10^{4}$

427 cells per well while LANA::ßla ${ }^{+}$cells were plated at a starting concentration of 100

428 cells per well. Three weeks after plating cells, reactivation was measured by

429 observation of cytopathic effect on the MEF cells.

$430 \quad$ Statistical analysis and software: Flow cytometric analysis was

431 performed using FlowJo V.10.0.8r1. Graphs were generated and statistical

432 analysis were performed using GraphPad Prism 7.0a. Limiting-dilution curves

433 were created by performing a non-linear regression, log(agonist) vs. response-

434 using the "EC anything" regression equation where $F$ was set to 63.2 , with top 
435 and bottom of the curves constrained to 100 and 0 respectively. Comparisons of

436 the LogECF were used to determine statistical significance. Unpaired student t-

437 tests were performed as mentioned. Quantitative-PCR data was analyzed using

438 the Pfaffl method [49] and graphed using GraphPad Prism 7.

441 1. Jha HC, Banerjee S, Robertson ES. The Role of Gammaherpesviruses in Cancer

442 Pathogenesis. Pathogens. 2016;5(1). Epub 2016/02/11. doi: 10.3390/pathogens5010018. PubMed PMID: 26861404; PubMed Central PMCID: 444 PMCPMC4810139.

4452 2. Elgui de Oliveira D. DNA viruses in human cancer: an integrated overview on 446 fundamental mechanisms of viral carcinogenesis. Cancer Lett. 2007;247(2):182-96. Epub 2006/07/04. doi: 10.1016/j.canlet.2006.05.010. PubMed PMID: 16814460.

$448 \quad 3$. Virgin HWt, Latreille P, Wamsley P, Hallsworth K, Weck KE, Dal Canto AJ, et al. Complete sequence and genomic analysis of murine gammaherpesvirus 68. J Virol. 1997;71(8):5894-904. Epub 1997/08/01. PubMed PMID: 9223479; PubMed

452

453

454

455

456

457

458

459

460

461

462

463

464

465

466 Central PMCID: PMCPMC191845.

4. Speck SH, Virgin HW. Host and viral genetics of chronic infection: a mouse model of gamma-herpesvirus pathogenesis. Curr Opin Microbiol. 1999;2(4):403-9. Epub 1999/08/25. PubMed PMID: 10458986.

5. Cai Q, Verma SC, Lu J, Robertson ES. Molecular biology of Kaposi's sarcomaassociated herpesvirus and related oncogenesis. Adv Virus Res. 2010;78:87-142. Epub 2010/11/03. doi: 10.1016/B978-0-12-385032-4.00003-3. PubMed PMID: 21040832; PubMed Central PMCID: PMCPMC3142360.

6. Speck SH, Ganem D. Viral latency and its regulation: lessons from the gammaherpesviruses. Cell Host Microbe. 2010;8(1):100-15. Epub 2010/07/20. doi:

10.1016/j.chom.2010.06.014. PubMed PMID: 20638646; PubMed Central PMCID: PMCPMC2914632.

7. Brown HJ, Song MJ, Deng H, Wu TT, Cheng G, Sun R. NF-kappaB inhibits gammaherpesvirus lytic replication. J Virol. 2003;77(15):8532-40. Epub 2003/07/15. PubMed PMID: 12857922; PubMed Central PMCID: PMCPMC165238. 8. Lieberman PM, Hu J, Renne R. Maintenance and replication during latency. In: Arvin A, Campadelli-Fiume G, Mocarski E, Moore PS, Roizman B, Whitley R, et al., editors. Human Herpesviruses: Biology, Therapy, and Immunoprophylaxis.

4709 9. Grinde B. Herpesviruses: latency and reactivation - viral strategies and host 471 response. J Oral Microbiol. 2013;5. Epub 2013/10/30. doi: 10.3402/jom.v5i0.22766. 472 PubMed PMID: 24167660; PubMed Central PMCID: PMCPMC3809354. 
473 10. Murata T, Tsurumi T. Switching of EBV cycles between latent and lytic states.

474 Rev Med Virol. 2014;24(3):142-53. Epub 2013/12/18. doi: 10.1002/rmv.1780.

475 PubMed PMID: 24339346.

476 11. Willer D0, Speck SH. Long-term latent murine Gammaherpesvirus 68

477 infection is preferentially found within the surface immunoglobulin D-negative

478

479

480 subset of splenic B cells in vivo. J Virol. 2003;77(15):8310-21. Epub 2003/07/15. PubMed PMID: 12857900; PubMed Central PMCID: PMCPMC165249.

481

482

483

484

485

486

487 12. Weck KE, Kim SS, Virgin HI, Speck SH. Macrophages are the major reservoir of latent murine gammaherpesvirus 68 in peritoneal cells. J Virol. 1999;73(4):327383. Epub 1999/03/12. PubMed PMID: 10074181; PubMed Central PMCID: PMCPMC104091.

13. Rekow MM, Darrah EJ, Mboko WP, Lange PT, Tarakanova VL. Gammaherpesvirus targets peritoneal B-1 B cells for long-term latency. Virology. 2016;492:140-4. Epub 2016/03/06. doi: 10.1016/j.virol.2016.02.022. PubMed PMID: 26945150; PubMed Central PMCID: PMCPMC4826794.

488 driven plasma cell differentiation regulates virus reactivation from latently infected B lymphocytes. PLoS Pathog. 2009;5(11):e1000677. Epub 2009/12/04. doi: 10.1371/journal.ppat.1000677. PubMed PMID: 19956661; PubMed Central PMCID: PMCPMC2777334.

15. Flano E, Husain SM, Sample JT, Woodland DL, Blackman MA. Latent murine gamma-herpesvirus infection is established in activated B cells, dendritic cells, and macrophages. J Immunol. 2000;165(2):1074-81. Epub 2000/07/06. PubMed PMID: 10878386.

16. Collins CM, Speck SH. Tracking murine gammaherpesvirus 68 infection of germinal center B cells in vivo. PLoS One. 2012;7(3):e33230. Epub 2012/03/20. doi:

500 10.1371/journal.pone.0033230. PubMed PMID: 22427999; PubMed Central PMCID: PMCPMC3302828.

501 17. Coleman CB, Nealy MS, Tibbetts SA. Immature and transitional B cells are

502

503

504 latency reservoirs for a gammaherpesvirus. J Virol. 2010;84(24):13045-52. Epub 2010/10/12. doi: 10.1128/JVI.01455-10. PubMed PMID: 20926565; PubMed Central PMCID: PMCPMC3004345.

505

506

507

508

509

510

18. Wilson SJ, Tsao EH, Webb BL, Ye H, Dalton-Griffin L, Tsantoulas C, et al. X box binding protein XBP-1s transactivates the Kaposi's sarcoma-associated herpesvirus (KSHV) ORF50 promoter, linking plasma cell differentiation to KSHV reactivation from latency. J Virol. 2007;81(24):13578-86. Epub 2007/10/12. doi:

511 19. Sun CC, Thorley-Lawson DA. Plasma cell-specific transcription factor XBP-1s

512

513

514

515

516

517

518 binds to and transactivates the Epstein-Barr virus BZLF1 promoter. J Virol. 2007;81(24):13566-77. Epub 2007/09/28. doi: 10.1128/JVI.01055-07. PubMed PMID: 17898050; PubMed Central PMCID: PMCPMC2168822.

20. Laichalk LL, Thorley-Lawson DA. Terminal differentiation into plasma cells initiates the replicative cycle of Epstein-Barr virus in vivo. J Virol. 2005;79(2):1296307. Epub 2004/12/23. doi: 10.1128/JVI.79.2.1296-1307.2005. PubMed PMID: 15613356; PubMed Central PMCID: PMCPMC538585. 
519 21. Li M, Lee H, Yoon DW, Albrecht JC, Fleckenstein B, Neipel F, et al. Kaposi's sarcoma-associated herpesvirus encodes a functional cyclin. J Virol.

521

522 1997;71(3):1984-91. Epub 1997/03/01. PubMed PMID: 9032330; PubMed Central PMCID: PMCPMC191282.

523

22. Chang Y, Moore PS, Talbot SJ, Boshoff CH, Zarkowska T, Godden $\mathrm{K}$, et al.

524

525

526 Cyclin encoded by KS herpesvirus. Nature. 1996;382(6590):410. Epub 1996/08/01. doi: 10.1038/382410a0. PubMed PMID: 8684480.

23. Arvanitakis L, Yaseen N, Sharma S. Latent membrane protein-1 induces cyclin

527

528

529

530

531

532

533

534

535

536

537

D2 expression, $\mathrm{pRb}$ hyperphosphorylation, and loss of TGF-beta 1-mediated growth inhibition in EBV-positive B cells. J Immunol. 1995;155(3):1047-56. Epub 1995/08/01. PubMed PMID: 7636179.

24. van Dyk LF, Hess JL, Katz JD, Jacoby M, Speck SH, Virgin HI. The murine gammaherpesvirus $68 \mathrm{v}$-cyclin gene is an oncogene that promotes cell cycle progression in primary lymphocytes. J Virol. 1999;73(6):5110-22. Epub 1999/05/11. PubMed PMID: 10233974; PubMed Central PMCID: PMCPMC112556. 25. Upton JW, van Dyk LF, Speck SH. Characterization of murine gammaherpesvirus $68 \mathrm{v}$-cyclin interactions with cellular cdks. Virology. 2005;341(2):271-83. Epub 2005/08/17. doi: 10.1016/j.virol.2005.07.014. PubMed PMID: 16102793.

538 26. Swanton C, Mann DJ, Fleckenstein B, Neipel F, Peters G, Jones N. Herpes viral cyclin/Cdk6 complexes evade inhibition by CDK inhibitor proteins. Nature.

540

541

542

543

544

545

546

547

548

549

550

551

552

553

554

555

556

557

558

559

560 1997;390(6656):184-7. Epub 1997/11/21. doi: 10.1038/36606. PubMed PMID: 9367157.

27. Williams LM, Niemeyer BF, Franklin DS, Clambey ET, van Dyk LF. A Conserved Gammaherpesvirus Cyclin Specifically Bypasses Host p18(INK4c) To Promote Reactivation from Latency. J Virol. 2015;89(21):10821-31. Epub 2015/08/21. doi: 10.1128/JVI.00891-15. PubMed PMID: 26292318; PubMed Central PMCID: PMCPMC4621100.

28. Niemeyer BF, Oko LM, Medina EM, Oldenburg DG, White DW, Cool CD, et al. Host Tumor Suppressor p18(INK4c) Functions as a Potent Cell-Intrinsic Inhibitor of Murine Gammaherpesvirus 68 Reactivation and Pathogenesis. J Virol. 2018;92(6). Epub 2018/01/05. doi: 10.1128/JVI.01604-17. PubMed PMID: 29298882; PubMed Central PMCID: PMCPMC5827403.

29. Nealy MS, Coleman CB, Li H, Tibbetts SA. Use of a virus-encoded enzymatic marker reveals that a stable fraction of memory B cells expresses latency-associated nuclear antigen throughout chronic gammaherpesvirus infection. J Virol. 2010;84(15):7523-34. Epub 2010/05/21. doi: 10.1128/JVI.02572-09. PubMed PMID: 20484501; PubMed Central PMCID: PMCPMC2897616.

30. van Dyk LF, Virgin HWt, Speck SH. The murine gammaherpesvirus $68 \mathrm{v}$ cyclin is a critical regulator of reactivation from latency. J Virol. 2000;74(16):745161. Epub 2000/07/25. PubMed PMID: 10906198; PubMed Central PMCID: PMCPMC112265.

561 31. Hoge AT, Hendrickson SB, Burns WH. Murine gammaherpesvirus 68 cyclin D 562

563 homologue is required for efficient reactivation from latency. J Virol. 2000;74(15):7016-23. Epub 2000/07/11. PubMed PMID: 10888640; PubMed

564 Central PMCID: PMCPMC112218. 
565 32. Diebel KW, Oko LM, Medina EM, Niemeyer BF, Warren CJ, Claypool DJ, et al.

566

567

568

569

570

571

572

573

574

575

576

577

578

579

580

581

582

583

584

585

586

587

588

589

590

591

592

593

594

595

596

597

598

599

600

601

602

603

604

605

606

607

608

609

610
Gammaherpesvirus small noncoding RNAs are bifunctional elements that regulate infection and contribute to virulence in vivo. MBio. 2015;6(1):e01670-14. Epub 2015/02/19. doi: 10.1128/mBio.01670-14. PubMed PMID: 25691585; PubMed Central PMCID: PMCPMC4337559.

33. van Dyk LF, Virgin HWt, Speck SH. Maintenance of gammaherpesvirus latency requires viral cyclin in the absence of B lymphocytes. J Virol.

2003;77(9):5118-26. Epub 2003/04/15. PubMed PMID: 12692214; PubMed Central PMCID: PMCPMC153990.

34. Tibbetts SA, Loh J, Van Berkel V, McClellan JS, Jacoby MA, Kapadia SB, et al.

Establishment and maintenance of gammaherpesvirus latency are independent of infective dose and route of infection. J Virol. 2003;77(13):7696-701. Epub 2003/06/14. PubMed PMID: 12805472; PubMed Central PMCID: PMCPMC164792.

35. Sunil-Chandra NP, Efstathiou S, Nash AA. Murine gammaherpesvirus 68 establishes a latent infection in mouse B lymphocytes in vivo. J Gen Virol. 1992;73 ( Pt 12):3275-9. Epub 1992/12/01. doi: 10.1099/0022-1317-73-12-3275. PubMed PMID: 1469366.

36. Herskowitz JH, Jacoby MA, Speck SH. The murine gammaherpesvirus 68 M2 gene is required for efficient reactivation from latently infected B cells. J Virol. 2005;79(4):2261-73. Epub 2005/02/01. doi: 10.1128/JVI.79.4.2261-2273.2005. PubMed PMID: 15681428; PubMed Central PMCID: PMCPMC546582.

37. Moser JM, Upton JW, Gray KS, Speck SH. Ex vivo stimulation of B cells latently infected with gammaherpesvirus 68 triggers reactivation from latency. J Virol. 2005;79(8):5227-31. Epub 2005/03/30. doi: 10.1128/JVI.79.8.5227-5231.2005. PubMed PMID: 15795307; PubMed Central PMCID: PMCPMC1069562.

38. Gangappa S, van Dyk LF, Jewett TJ, Speck SH, Virgin HWt. Identification of the in vivo role of a viral bcl-2. J Exp Med. 2002;195(7):931-40. Epub 2002/04/03.

PubMed PMID: 11927636; PubMed Central PMCID: PMCPMC2193719.

39. Tibbetts SA, van Dyk LF, Speck SH, Virgin HWt. Immune control of the number and reactivation phenotype of cells latently infected with a gammaherpesvirus. J Virol. 2002;76(14):7125-32. Epub 2002/06/20. PubMed PMID: 12072512; PubMed Central PMCID: PMCPMC136321.

40. Lieberman PM. Keeping it quiet: chromatin control of gammaherpesvirus latency. Nat Rev Microbiol. 2013;11(12):863-75. Epub 2013/11/07. doi: 10.1038/nrmicro3135. PubMed PMID: 24192651; PubMed Central PMCID: PMCPMC4544771.

41. Niedobitek G, Meru N, Delecluse HJ. Epstein-Barr virus infection and human malignancies. Int J Exp Pathol. 2001;82(3):149-70. Epub 2001/08/08. PubMed PMID: 11488990; PubMed Central PMCID: PMCPMC2517709.

42. Hussain T, Mulherkar R. Lymphoblastoid Cell lines: a Continuous in Vitro Source of Cells to Study Carcinogen Sensitivity and DNA Repair. Int J Mol Cell Med. 2012;1(2):75-87. Epub 2012/04/01. PubMed PMID: 24551762; PubMed Central PMCID: PMCPMC3920499.

43. Siliciano RF, Greene WC. HIV latency. Cold Spring Harb Perspect Med. 2011;1(1):a007096. Epub 2012/01/10. doi: 10.1101/cshperspect.a007096. PubMed PMID: 22229121; PubMed Central PMCID: PMCPMC3234450. 
611 44. Lee GQ, Lichterfeld M. Diversity of HIV-1 reservoirs in CD4+ T-cell

612 subpopulations. Curr Opin HIV AIDS. 2016;11(4):383-7. Epub 2016/03/30. doi:

613 10.1097/COH.0000000000000281. PubMed PMID: 27023286; PubMed Central

614 PMCID: PMCPMC4915926.

615 45. Datta PK, Kaminski R, Hu W, Pirrone V, Sullivan NT, Nonnemacher MR, et al.

616 HIV-1 Latency and Eradication: Past, Present and Future. Curr HIV Res.

617 2016;14(5):431-41. Epub 2016/03/25. PubMed PMID: 27009094; PubMed Central

618 PMCID: PMCPMC5157928.

619 46. Baxter AE, Niessl J, Fromentin R, Richard J, Porichis F, Charlebois R, et al.

620 Single-Cell Characterization of Viral Translation-Competent Reservoirs in HIV-

621 Infected Individuals. Cell Host Microbe. 2016;20(3):368-80. Epub 2016/08/23. doi:

622 10.1016/j.chom.2016.07.015. PubMed PMID: 27545045; PubMed Central PMCID:

623 PMCPMC5025389.

624 47. Lee KS, Suarez AL, Claypool DJ, Armstrong TK, Buckingham EM, van Dyk LF.

625 Viral cyclins mediate separate phases of infection by integrating functions of distinct

626 mammalian cyclins. PLoS Pathog. 2012;8(2):e1002496. Epub 2012/02/10. doi:

627 10.1371/journal.ppat.1002496. PubMed PMID: 22319441; PubMed Central PMCID:

628 PMCPMC3271081.

629 48. Weck KE, Barkon ML, Yoo LI, Speck SH, Virgin HI. Mature B cells are required

630 for acute splenic infection, but not for establishment of latency, by murine

631 gammaherpesvirus 68. J Virol. 1996;70(10):6775-80. Epub 1996/10/01. PubMed

632 PMID: 8794315; PubMed Central PMCID: PMCPMC190721.

633 49. Pfaffl MW. A new mathematical model for relative quantification in real-time

634 RT-PCR. Nucleic Acids Res. 2001;29(9):e45. Epub 2001/05/09. PubMed PMID:

635 11328886; PubMed Central PMCID: PMCPMC55695. 
Figure 1. Characterization of the cyclin-deficient virus expressing a LANA $\beta$-lactamase gene fusion. (A) Schematic of wild-type virus (top), the cyclin deficient virus (second), the wild-type $\beta$-lactamase marked virus (third), and the cyclin deficient $\beta$-lactamase marked virus (bottom). Viruses described as in van Dyk 2000 and Niemeyer 2018. (B) Identification of infected cells by flow cytometry using $\beta$-lactamase ( $\beta \mid a)$. 3T12 cells were infected with either wild-type unmarked HV68, WT.ßla, or cyckO.ßla at an MOI of $10 \mathrm{pfu} /$ cell. Cells were harvested at $12 \mathrm{hpi}$ and infected cells were identified by $\beta$-lactamase activity. LANA::ßla+ cells are contained within the upper right polygonal gate. Average LANA::Bla+ frequencies are indicated +/-SEM n=2. (C) B6 mice were infected via IP infection with WT.ßla (black) or cycKO.ßla (red) viruses. At 42 dpi splenocytes (left panel) and peritoneal cells (right panel) from infected mice were plated on MEFs in a limiting-dilution fashion. Comparison of reactivation from infected cells were pooled for reactivation analysis. For each virus group 5 mice were infected and pooled for reactivation analysis.

Figure 2: Cyclin deficient virus has a similar cellular distribution to wild-type $\mathrm{HV} 68$ during primary infection of C57BL/6J mice. (A) Representative gating of LANA::ßla+ splenocytes. (B) Representative gating strategy for total B cells (CD19+), germinal center B cells (CD19+, IgD-, CD38-), and activated B cells (CD19+, IgD-, CD44+). (C) and (D) representative histograms of cell surface marker expression after infection with WT.ßla or cycKO.ßla virus on total cells (dark grey WT.ßla and light grey cycKO.ßla), WT.ßla infected LANA::ßla+ cells (black), or cycKO.ßla infected LANA::ßla + cells (red). Cells were harvested at either $8 \mathrm{dpi}(\mathrm{C})$ or $16 \mathrm{dpi}(\mathrm{D})$. (E) Quantification of the frequency of cells expressing cell surface markers using the gating strategy outlined in (B) with SEM shown. 8 dpi CD19, IgD and CD38 $n=13.8$ DPI CD44 n=7.16 DPI $n=11$. Two-tailed student $t$ tests were performed to measure statistical significance.

Figure 3. Disruption of the viral cyclin has no effect on the frequency of viral genome positive cells yet results in a reduced frequency of LANA::ßla+ cells. Mice were infected via IP injection with WT.ßla or cycKO.ßla viruses and 
splenocytes were harvested at 8 or $16 \mathrm{dpi}$. (A) Limiting-dilution nested PCR of viral gene ORF 50 from WT. $\beta l a$ or cycKO.Bla infected splenocytes. $n=4$ ( $8 \mathrm{dpi}$ ) or $n=3$ (16 dpi) with 3-5 mice pooled per group with SEM shown. Comparisons between the $\operatorname{LogEC}(63.2)$ found statistical difference between the of WT.ßla and cycKO.ßla at $8 \mathrm{dpi}$ only ( $p=0.009)$. (B) Representative pseudocolor plots identifying LANA::ßla+ splenocytes, indicated in the upper right polygon. Average frequencies of LANA::ßla+ cells +/- SEM is indicated below the gate. $8 \mathrm{dpi}$ is shown on the left, while $16 \mathrm{dpi}$ is shown on the right, with WT.ßla infected mice on top and cycKO.ßla infected mice on bottom. (C) Percent of LANA::Bla+ cells (top) and total number of LANA::ßla+ splenocytes (bottom) from each individual mouse plotted with SEM shown after infection with WT.ßla (black) or cycKO.ßla (red) virus. (D) Graphical representation of the number of LANA::ßla+ cells expressing cell surface markers with SEM shown after infection with WT.ßla (black) or cycK.ßla (red) virus. Cells were stained and gated as in figure 2. 8 dpi: LANA::ßla+, CD19, $\operatorname{lgD}$, and $\operatorname{CD} 38 \mathrm{n}=13$ and $\mathrm{CD} 44 \mathrm{n}=7.16 \mathrm{dpi} n=11$. Two-tailed student $\mathrm{t}$ tests were performed to measure statistical significance in $C$ and $D$.

\section{Figure 4. Disruption of the viral cyclin results in a reduced frequency of LANA:: $\beta$ la expressing cells in the} peritoneum of C57BL/6J mice. Mice were infected via IP injection with WT.ßla or cycKO.ßla viruses and peritoneal cells were harvested at 8 or $16 \mathrm{dpi}$. (A) Representative gating strategy for peritoneal cells. (B) Representative histograms of cell surface marker expression after infection with WT.ßla or cycKO.ßla virus on total cells (dark grey WT.ßla and light grey cycKO.ßla), WT.ßla ßla+cells (black), or cycKO.ßla $\beta l a+$ cells (red) at 8 dpi (top panel) and 16 dpi (bottom panel). (C) Representative pseudocolor plots identifying $\beta$ la+ cells in the upper right polygon at $8 \mathrm{dpi}$ (left panel) or $16 \mathrm{dpi}$ (right panel) after WT.ßla (top) or cycKO.ßla (bottom) virus infection. The frequency of peritoneal cells that are $\beta l a+$ is indicated below the gate $+/$-SEM. (D) Percent of cells that are $\beta l a+$ with $+/$-SEM shown after infection with WT. $\beta$ la (black) or cycKO.ßla (red) virus. 8 dpi: WT. $\beta l a ~ n=9$ and cycKO.ßla n=10. 16 dpi: $\mathrm{n}=11$. Two-tailed student $\mathrm{t}$ tests were performed to identify statistical significance.

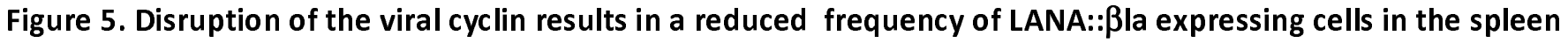
of CD8-/- mice. At $16 \mathrm{dpi}$, splenocytes were collected and stained for $\beta$-lactamase activity and cell surface markers 
CD19, CD38, and IgD. CD38 and IgD samples have been previously gated on CD19+ cells. (A) Representative pseudocolor plots are shown identifying LANA::ßla+ cells (top row). LANA::ßla+ cells are found within the upper right polygon with the average percent of cells expressing LANA::ßla +/- SEM indicated below the gate. Expression of CD19, IgD, and CD38 on total cells after WT.ßla virus or cycKO.ßla virus infection is shown in the indicated columns. Expression of CD19, IgD, and CD38 on LANA::ßla+ cells is shown in the indicated columns. The average percent of cells that fall within each gate is indicated +/-SEM. (B) Graphical representation of the percent of cells that are LANA::ßla+ after WT.ßla (black) or cycKO.ßla (red) infection with SEM. (C) Graphed are the average percent of cells that are CD19+ and the percent of CD19+ cells that are IgD+/CD38-, IgD+/CD38+, IgD-/CD38+, and IgD-/CD38- after WT.ßla (black) or cycKO.ßla (red) infection. Total cells are graphed on the top while LANA::ßla+ gated cells are shown on the bottom, both with SEM plotted. Two experiments were performed with 3-4 WT. Bla and cycKO.ßla infected mice per experiment. WT.ßla: $n=7 ;$ cycKO.ßla: $n=6$

\section{Figure 6. Disruption of the viral cyclin results in a reduced frequency of LANA:: $\beta$ la expressing cells in the}

peritoneum of CD8-/- mice. CD8-/- mice were inoculated with WT. ßla virus or cycKO.ßla virus via IP injection. At $16 \mathrm{dpi}$, peritoneal cells were collected and stained for $\beta$-lactamase activity and cell surface markers CD19, B220, and CD5. (A) Representative pseudocolor plots are shown identifying LANA::Bla+ cells (top row). LANA::ßla+ cells are found within the upper right polygon with the average percent of cells expressing LANA::ßla +/- SEM indicated below the gate. Expression of CD19, B220, and CD5 on total cells after WT.ßla virus or cycKO.ßla virus infection is shown in the indicated columns. Expression of CD19, B220, and CD5 on LANA::ßla+ cells is shown in the indicated columns. The average percent of cells that fall within each gate is indicated +/- SEM. (B) Graphical representation of the percent of cells that are LANA::ßla+ after WT.ßla (black) or cycKO.ßla (red) infection with SEM. (C) Graphed are the average percent of cells that are CD19+, B1-a (CD5+), B1-b (B220 intermediate), and B2 (B220 high) after WT.ßla (black) or cycKO.ßla (red) infection. Total cells are graphed on the top while LANA::ßla+ gated cells are shown on the bottom, both with SEM plotted. Two experiments were performed with 3-4 WT. ßla and cycKO.ßla infected mice per experiment. WT. $\beta l a: n=6$ cycKO. $\beta l a: n=7$. (D) Relative expression of $\beta$-lactamase (top) and LANA 
(bottom). RNA was isolated from infected peritoneal cells and subjected to quantitative RT-PCR analysis using primers directed against $\beta$-lactamase (top) and LANA (bottom). mRNA expression levels depicted were normalized to $18 \mathrm{~S}$ levels, with differences between WT. Bla and cycKO.ßla as noted.

Figure 7. The viral cyclin is dispensable for reactivation in latently infected cells that express LANA::Bla. (A) Experiment schematic. CD8-/- mice were infected via IP injection with WT. ßla or cycKO.ßla viruses and peritoneal cells were harvested at $16 \mathrm{dpi}$. Cells were stained for $\beta$-lactamase activity and LANA::ßla+ cells were sorted by FACS. (B) Gating strategy of LANA::ßla sort (left) and purity of post-sort WT.ßla infected LANA::Bla+ cells (right). LANA::ßla+ cells are located in the upper right polygon and LANA::ßla- cells are located in the upper left polygon. The percent of events within each gate is indicated below the gate. (C) WT.ßla (black) and cycKO.ßla (red) infected pre-sorted (left), LANA::ßla- (middle), and LANA::ßla+ (right) cells were subjected to limiting-dilution reactivation analysis. Reactivation was measured 21 days after plating sorted and pre-sorted cells on permissive MEFs. Linear regression with comparison of the $\operatorname{LogEC}(63.2)$ found that there was a statistical difference in reactivation between LANA::ßla+ WT.ßla and cycKO.ßla infected cells and pre-sorted WT.ßla and cycKO.ßla infected cells $(p<0.0001) . n=2$ independent experiments with a total of 15 WT. Bla infected mice and 30 cycKO.ßla infected mice. The table below lists the number of cells plated to reach CPE in $63.2 \%$ (the dotted line) of the wells plated for reactivation, corresponding to the number of cell required to find at least 1 reactivating cell.

\section{Figure 8. The viral cyclin drives reactivation through increasing the pool of LANA expressing, reactivation-}

competent, infected cells. Wild-type yHV68 infection results in establishment of latency (depicted by nuclear viral episomes). At least two distinct populations of latently infected cells arise, cells expressing viral LANA (gray) and those lacking detectable LANA expression (white). The LANA expressing cells are permissive to reactivation and will readily reactivate when triggered. Latent cells lacking LANA are incapable of reactivation, and instead remain dormant in latency. Infection with a viral cyclin-deficient pHV68 virus also results in establishment of latency, with equivalent numbers to wild-type infection. However, without the viral cyclin, latency is skewed to reactivation incompetent, LANA negative cells. The cyclin-deficient infected cells which do express LANA are still able to 
bioRxiv preprint doi: https://doi.org/10.1101/761700; this version posted September 9, 2019. The copyright holder for this preprint (which was not certified by peer review) is the author/funder. All rights reserved. No reuse allowed without permission.

reactivate, as efficiently as wild-type, but there are diminished numbers of these cells ultimately leading to the reactivation defect. 
Figure 1: Characterization of the cyclin-deficient virus expressing a LANA $\beta$-lactamase gene fusion.

A.

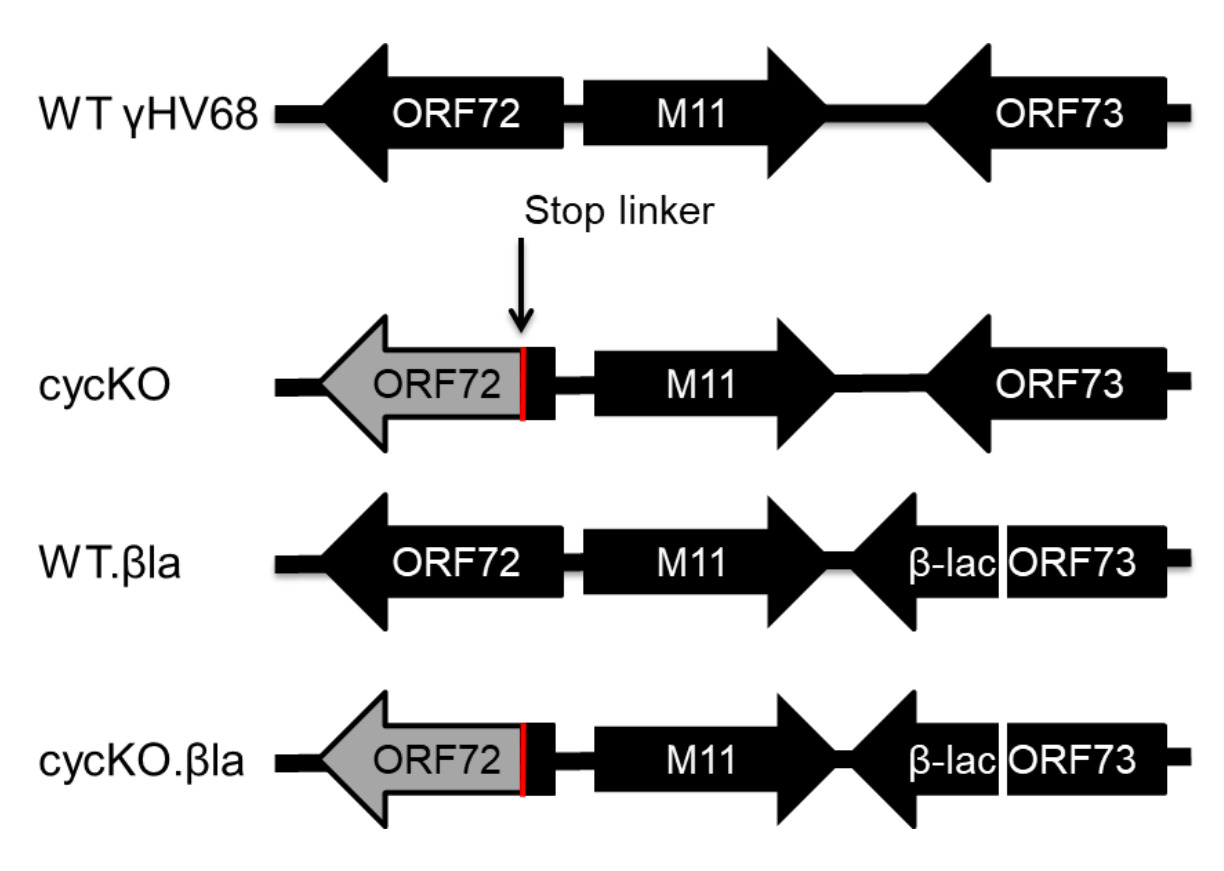

C.

Splenocytes

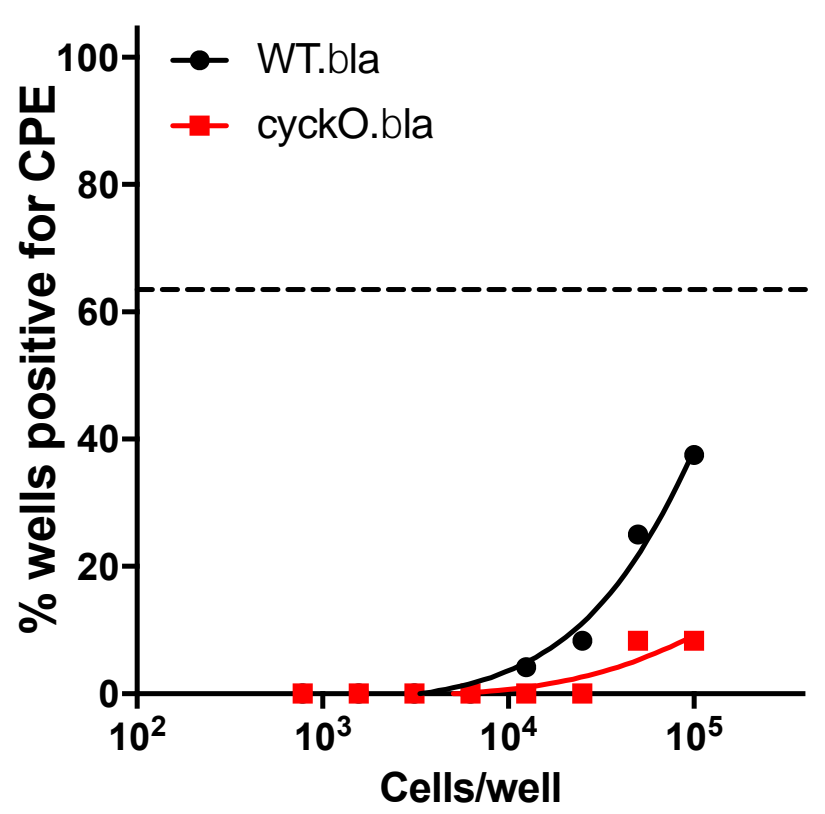

Peritoneal Cells

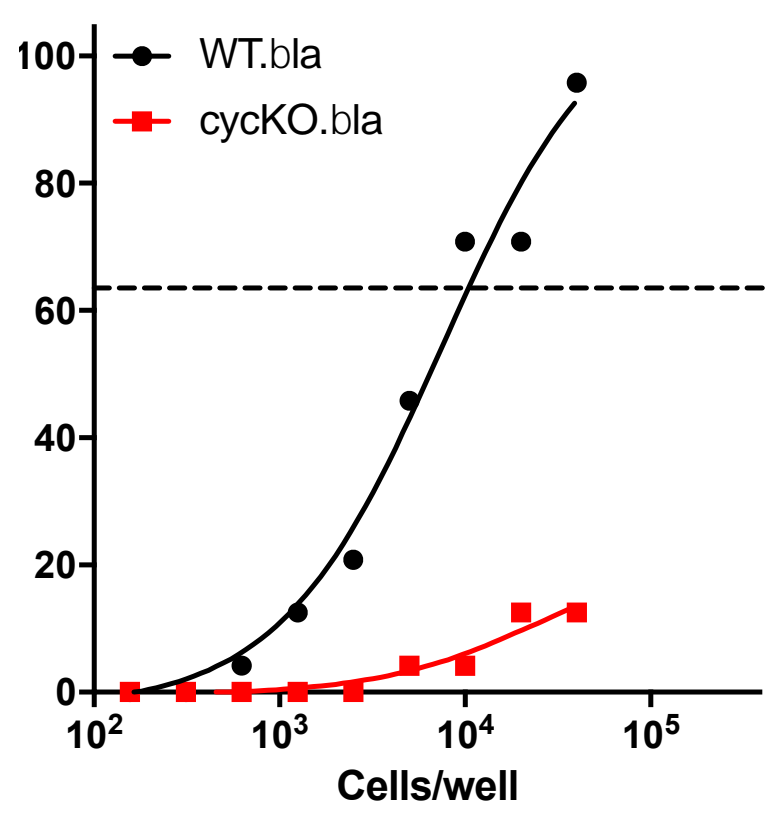

B.

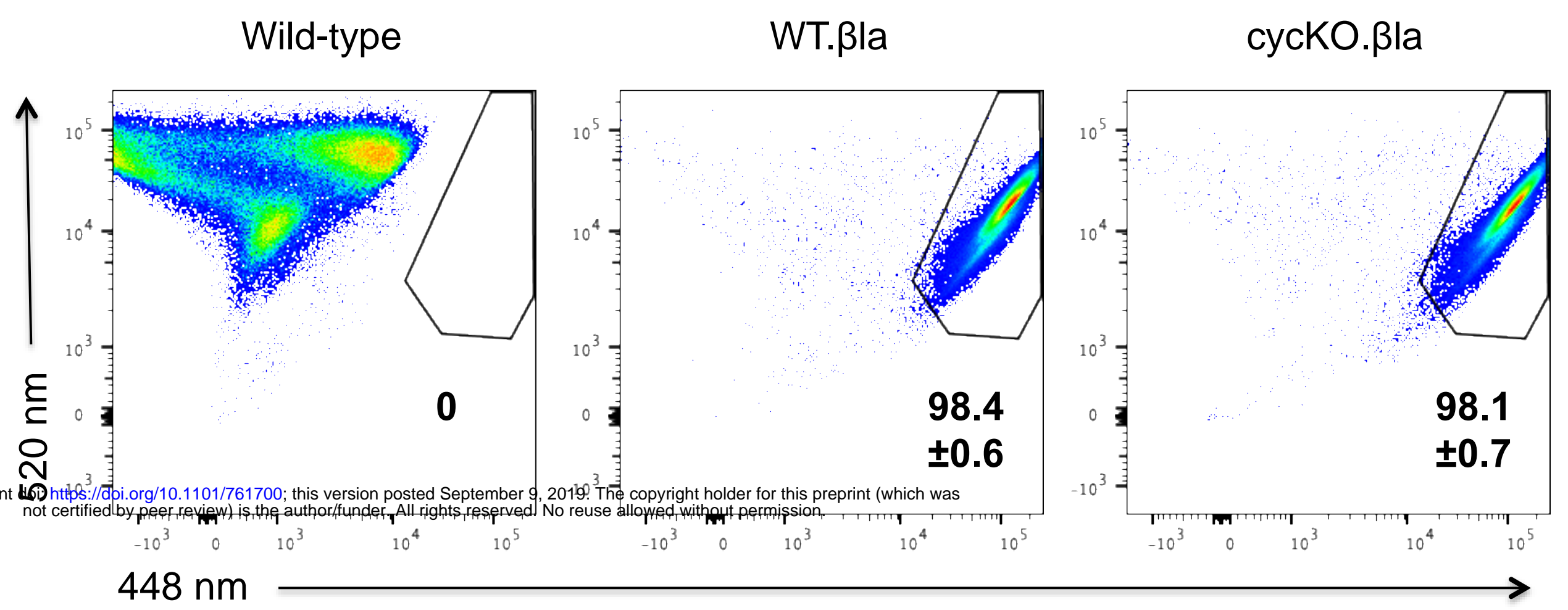


Figure 2: Cyclin deficient virus has a similar cellular distribution to wild-type $\mathrm{YHV68}$ during primary infection of C57BL/6J mice

A.

Mock infected

WT.ßla infected

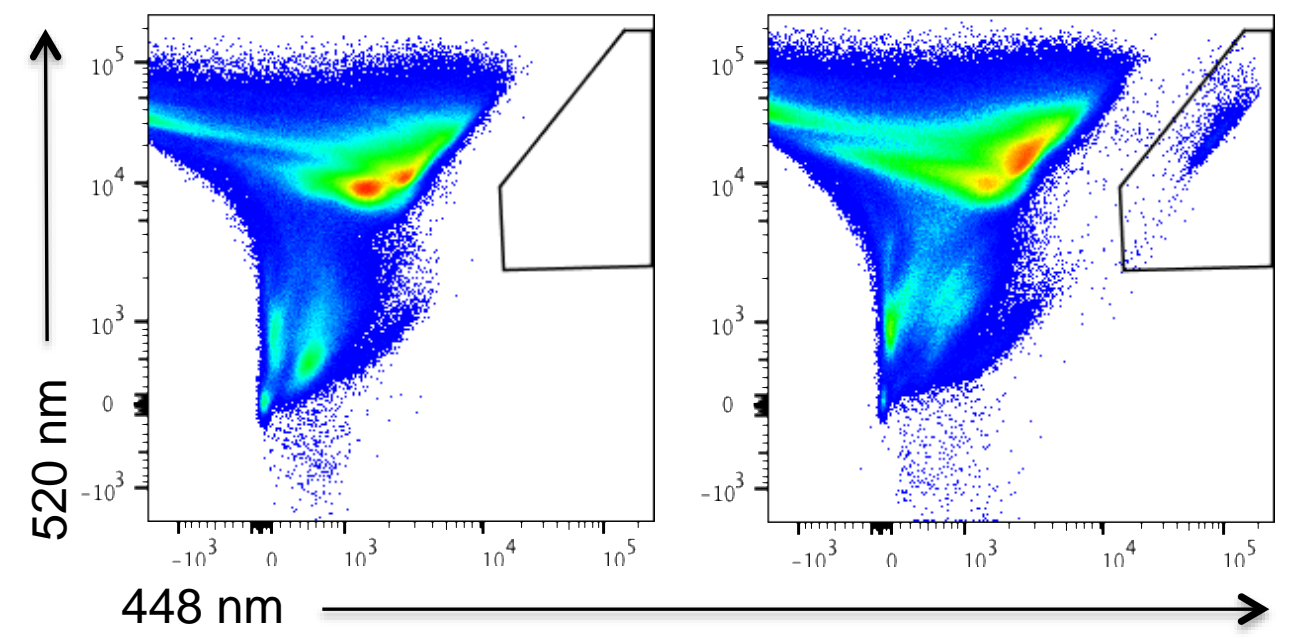

$B$.

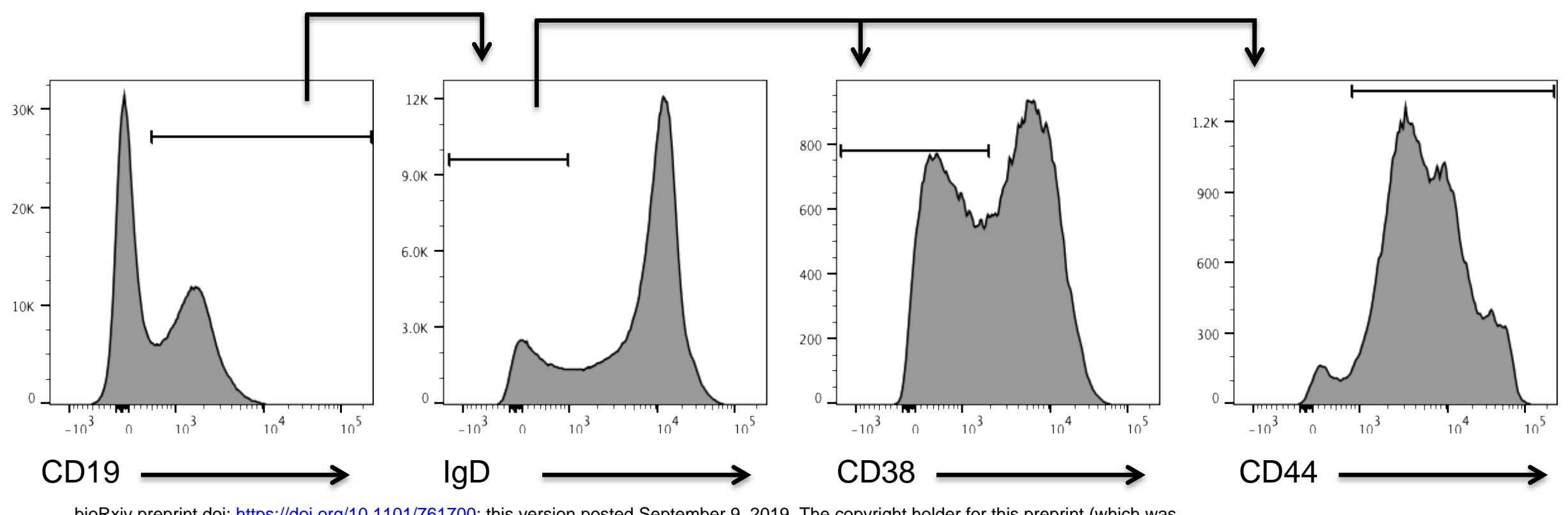

C. Rxiv preprint doi: https://doi.org/10.1101/761700; this version posted September 9 , 2019. The copyright holder for this prept
not certified by peer review) is the authorffunder. All rights reserved. No reuse allowed without permission.

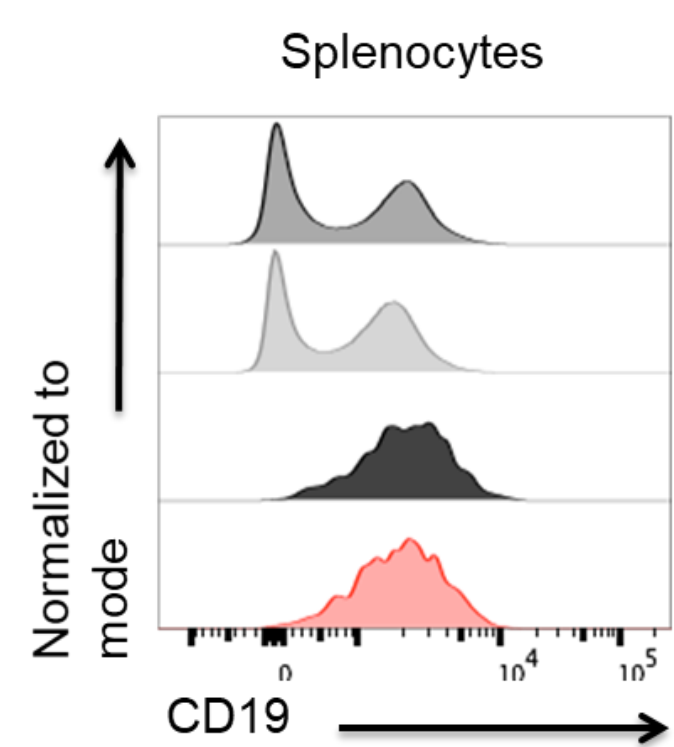

D.

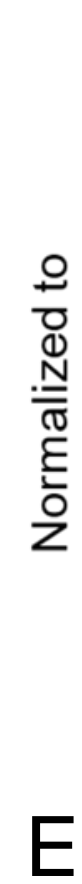

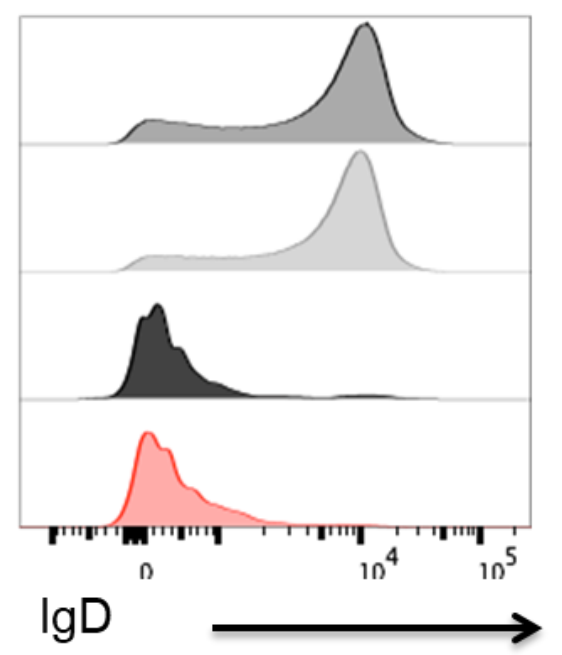

Gated on CD19+
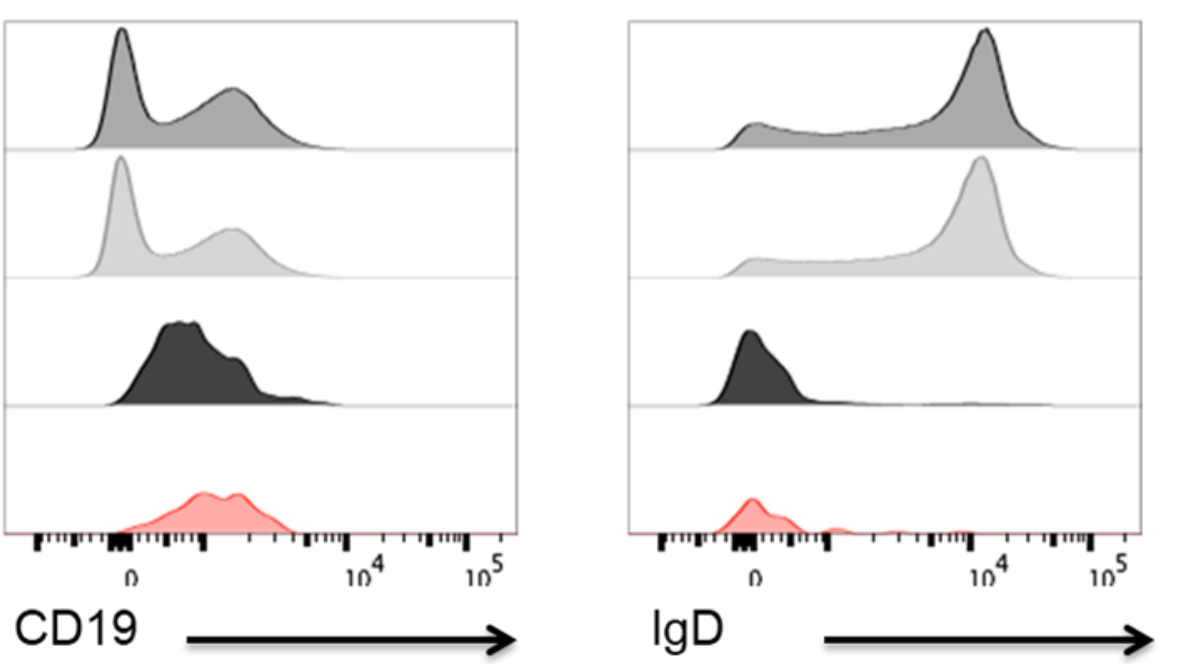

$\lg$
Gated on CD19+ IgD-
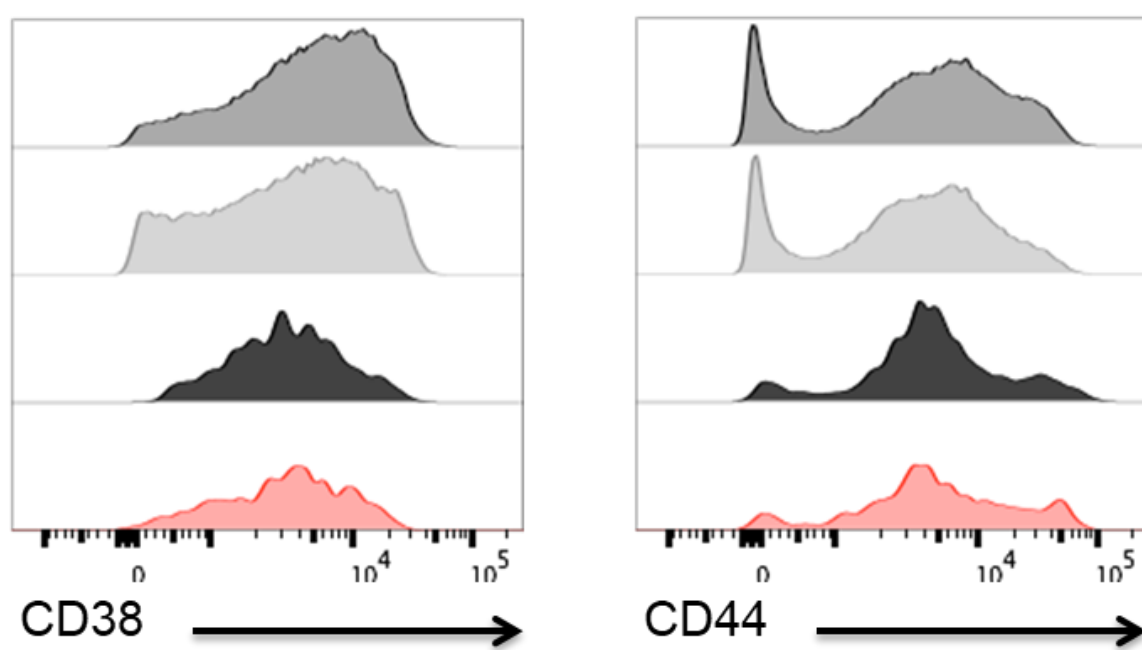

Gated on CD19+ IgD-
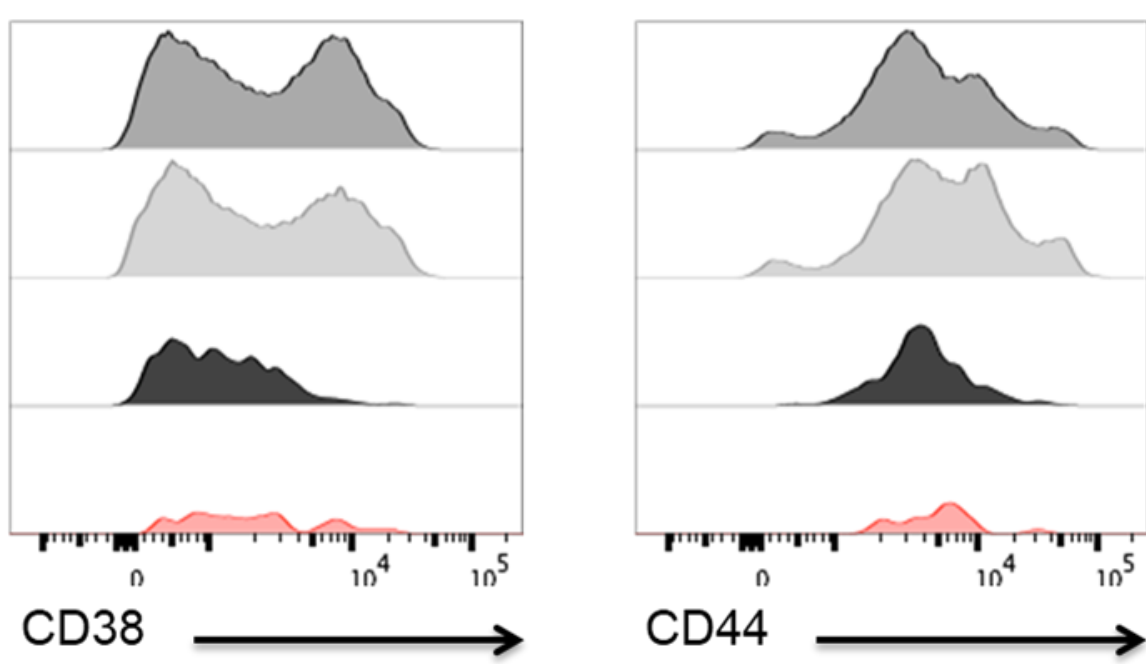

Total cells, WT.ßla

Total cells, cycKO.ßla

LANA::ßla+ cells, WT.ßla

LANA::ßla+ cells, cycKO.ßla
Total cells, cycKO.ßla

LANA::ßla+ cells, WT.ßla

LANA::ßla+ cells, cycKO.ßla
CD44

16 dpi
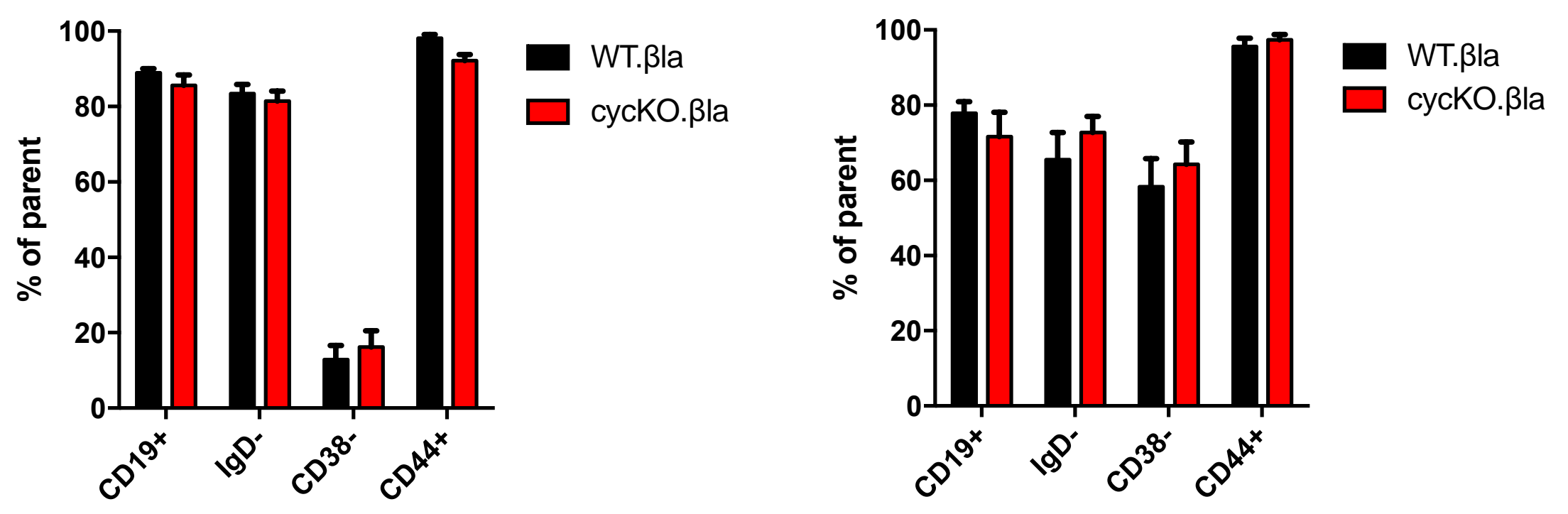
Figure 3: Disruption of the viral cyclin has no effect on the frequency of viral genome positive cells yet results in a

A.

B.
D.
D.

B.
D.
D.

$8 \mathrm{dpi}$
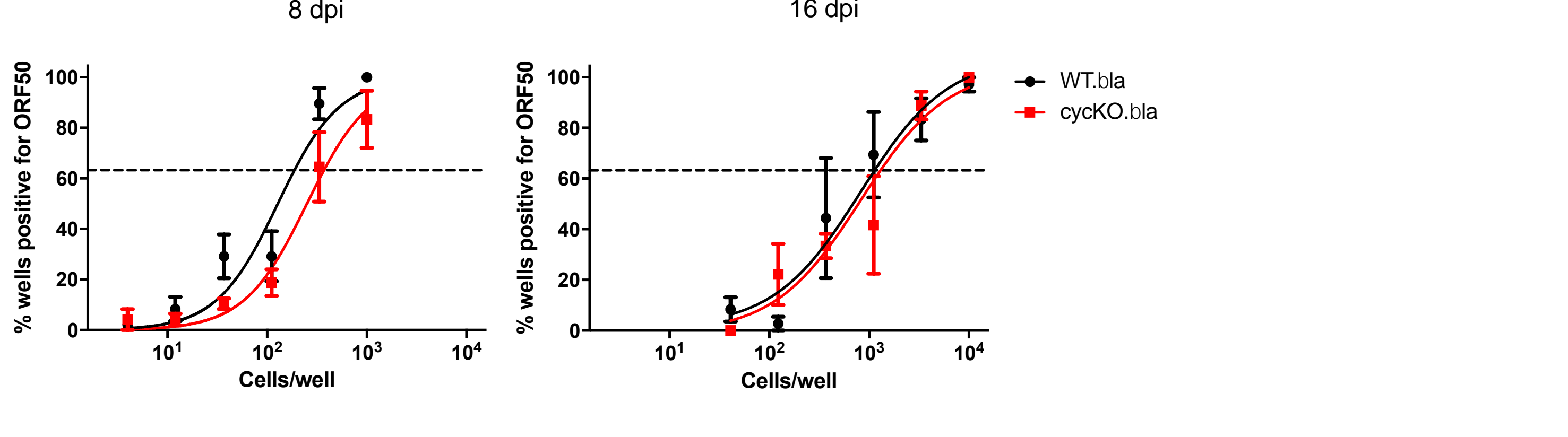

bioRxiv preprint doi: https:///oli.org/10.1101/761700; this version posted SeptemBer 9, 2019. The Eopyright holder for this preprint (which was
cycKO. ßla

8 dpi

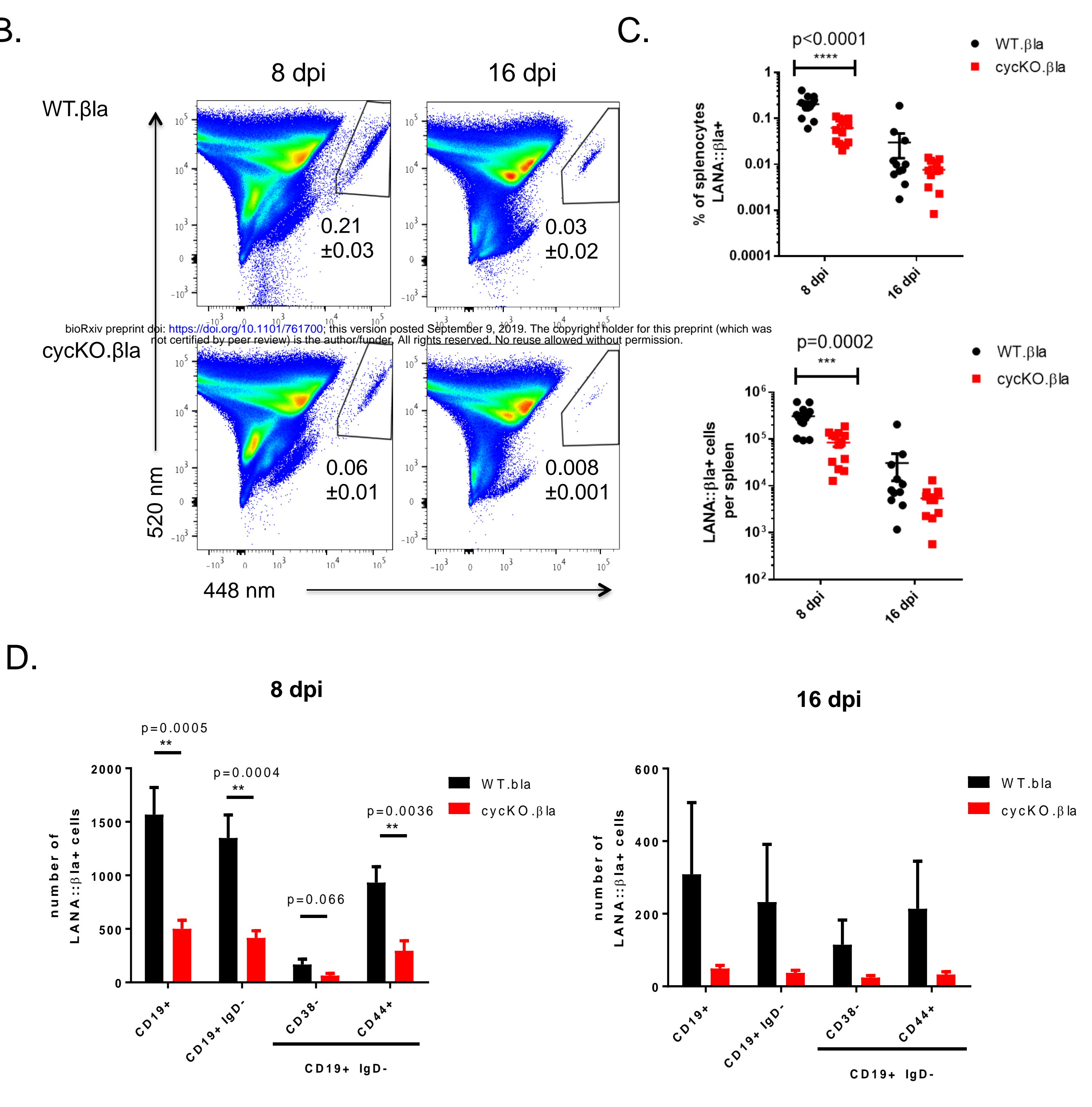

C.
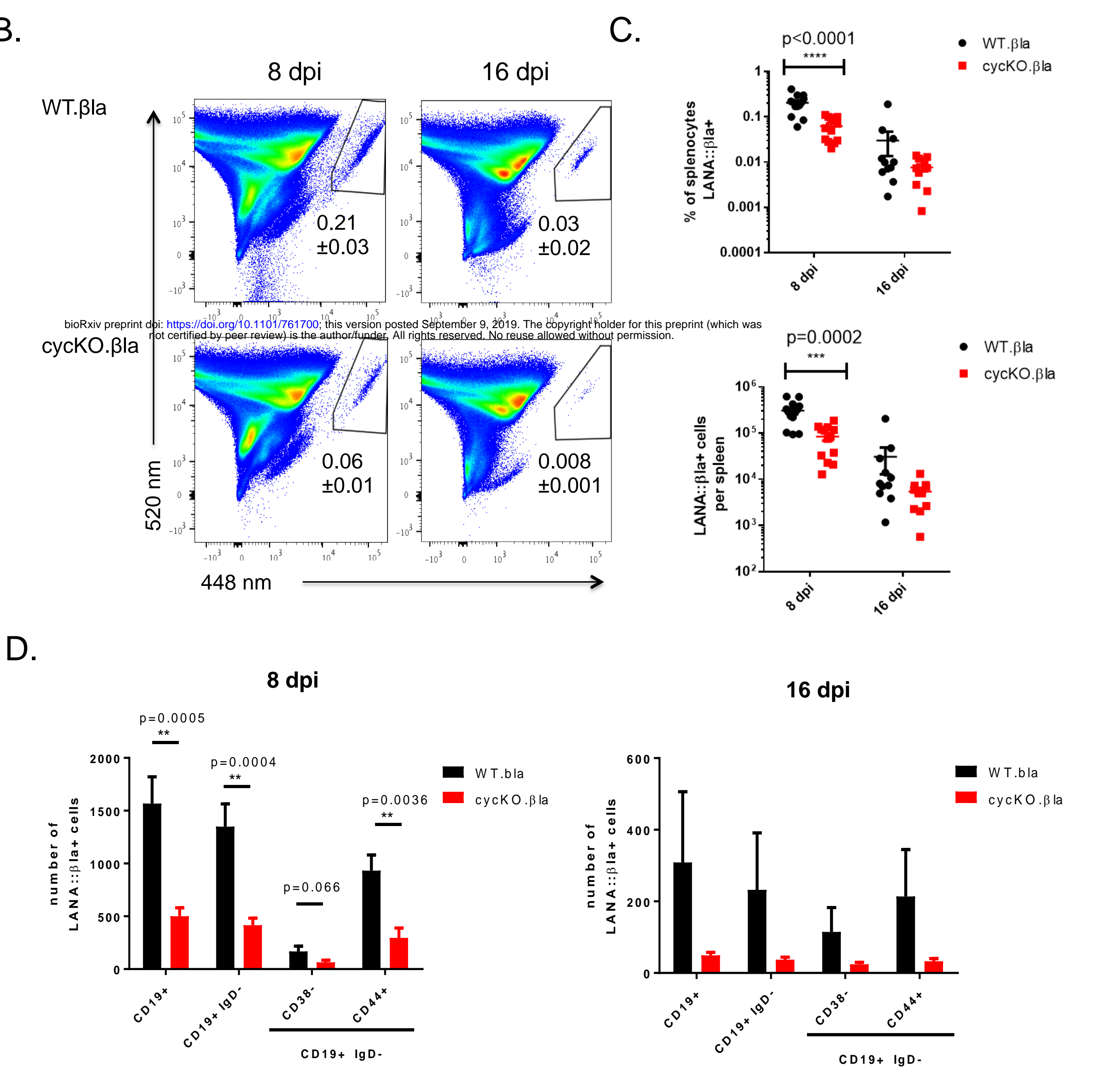

16 dpi
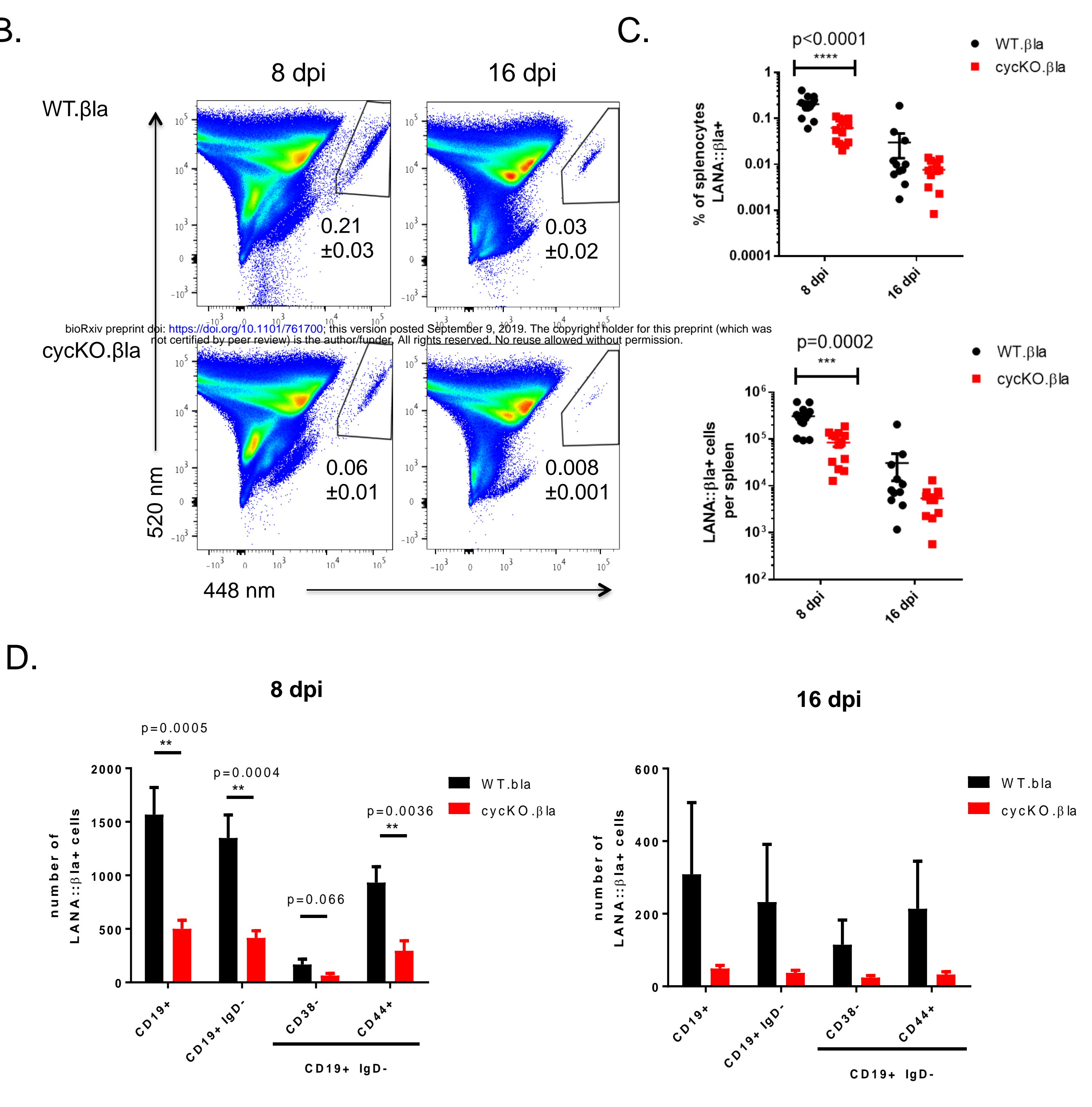

$16 \mathrm{dpi}$

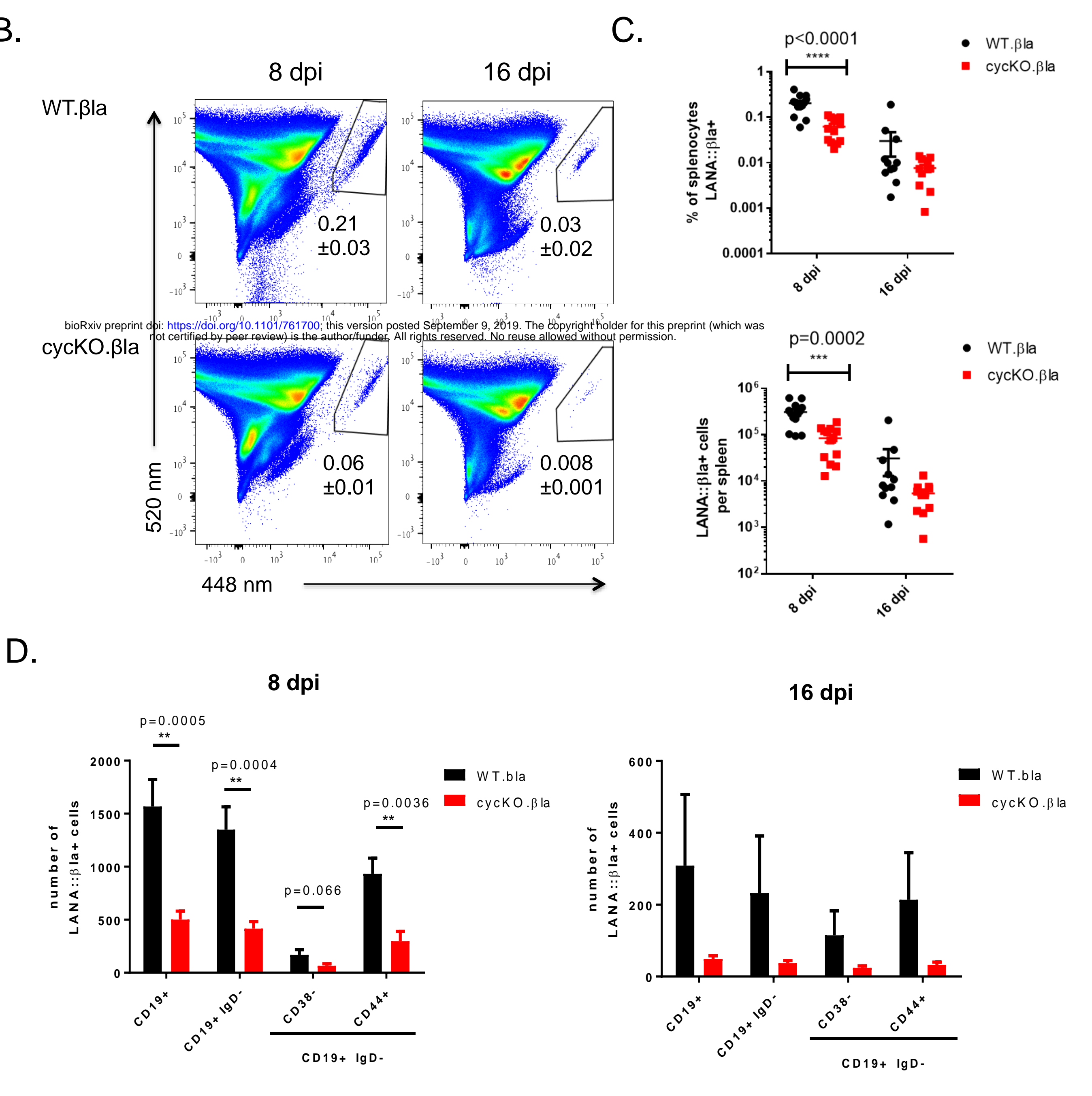

.

$$
\text { . }
$$

\section{reduced frequency of LANA::ßla+ cells}

.

(1)

(1)

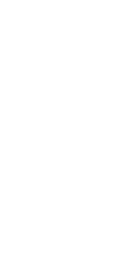
(1) (1) 更

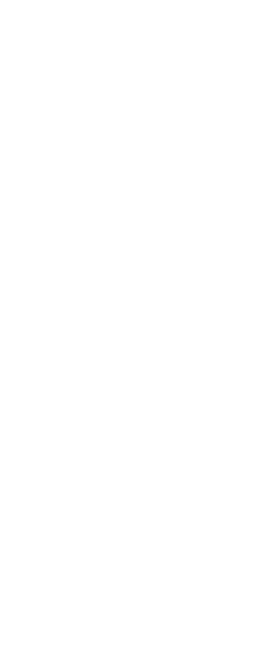


Figure 4: Disruption of the viral cyclin results in a reduced frequency of LANA:: $\beta$ la expressing cells in the peritoneum of C57BL/6J mice

A.

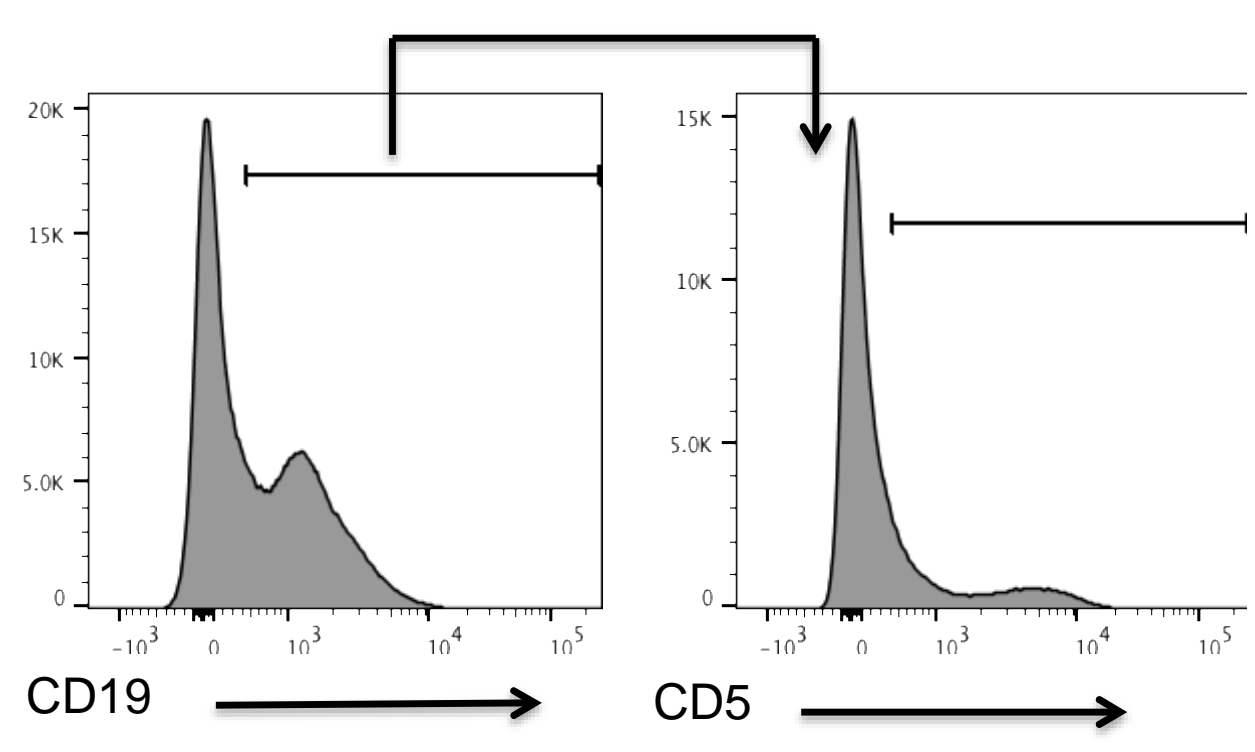

B.

$8 \mathrm{dpi}$
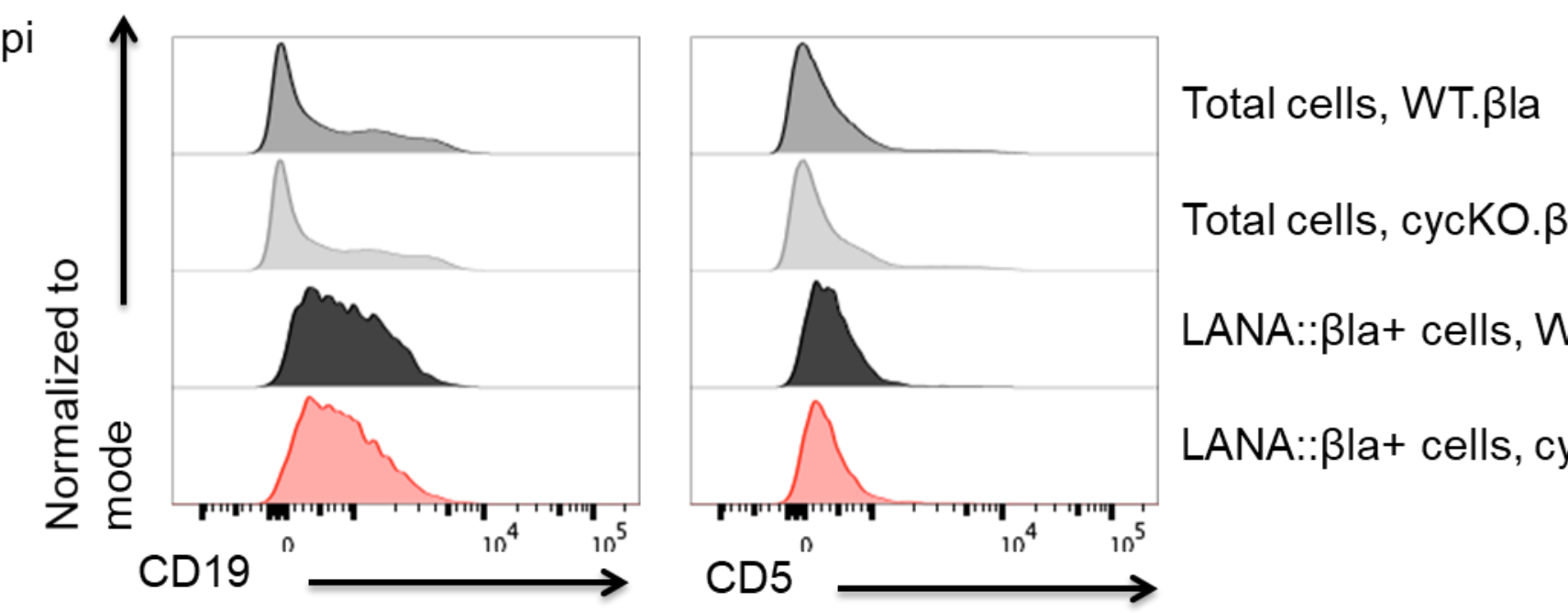

Total cells, cycKO.ßla

LANA::ßla+ cells, WT.ßla LANA::ßla+ cells, cycKO.ßla

$16 \mathrm{dp}$

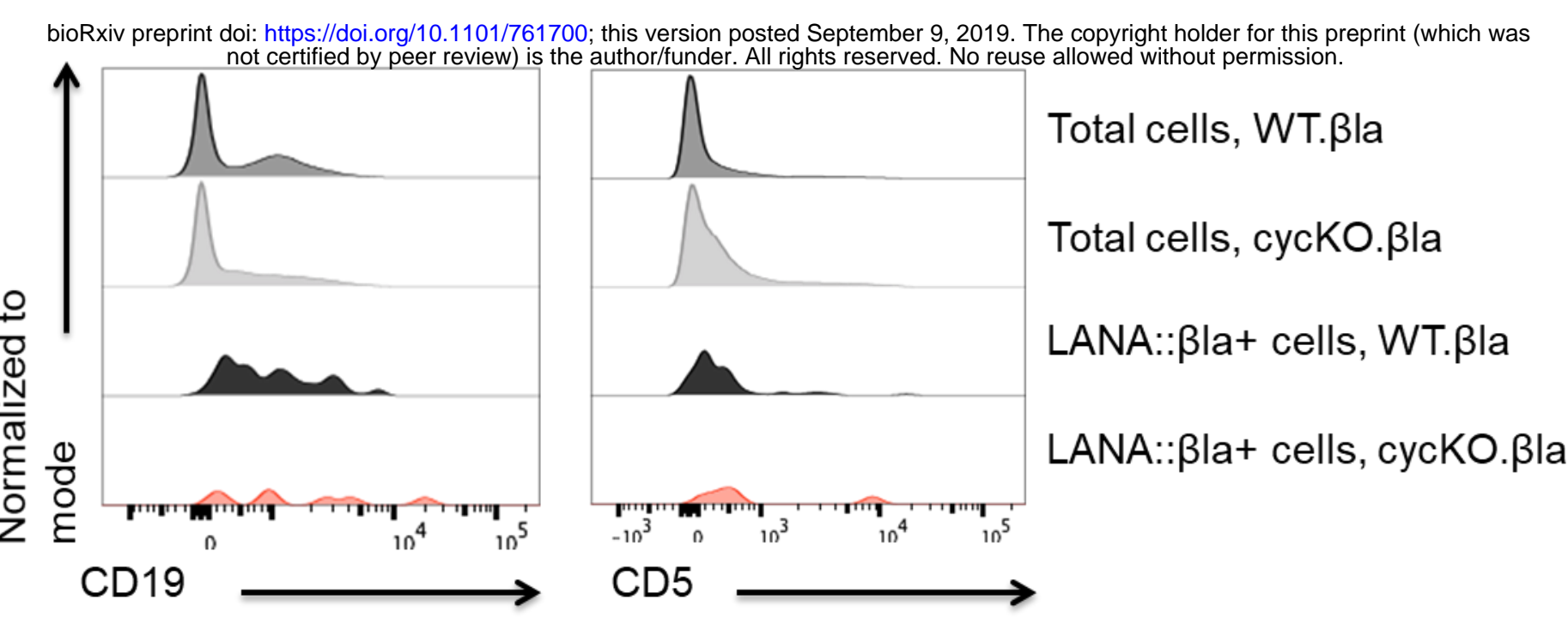

C.

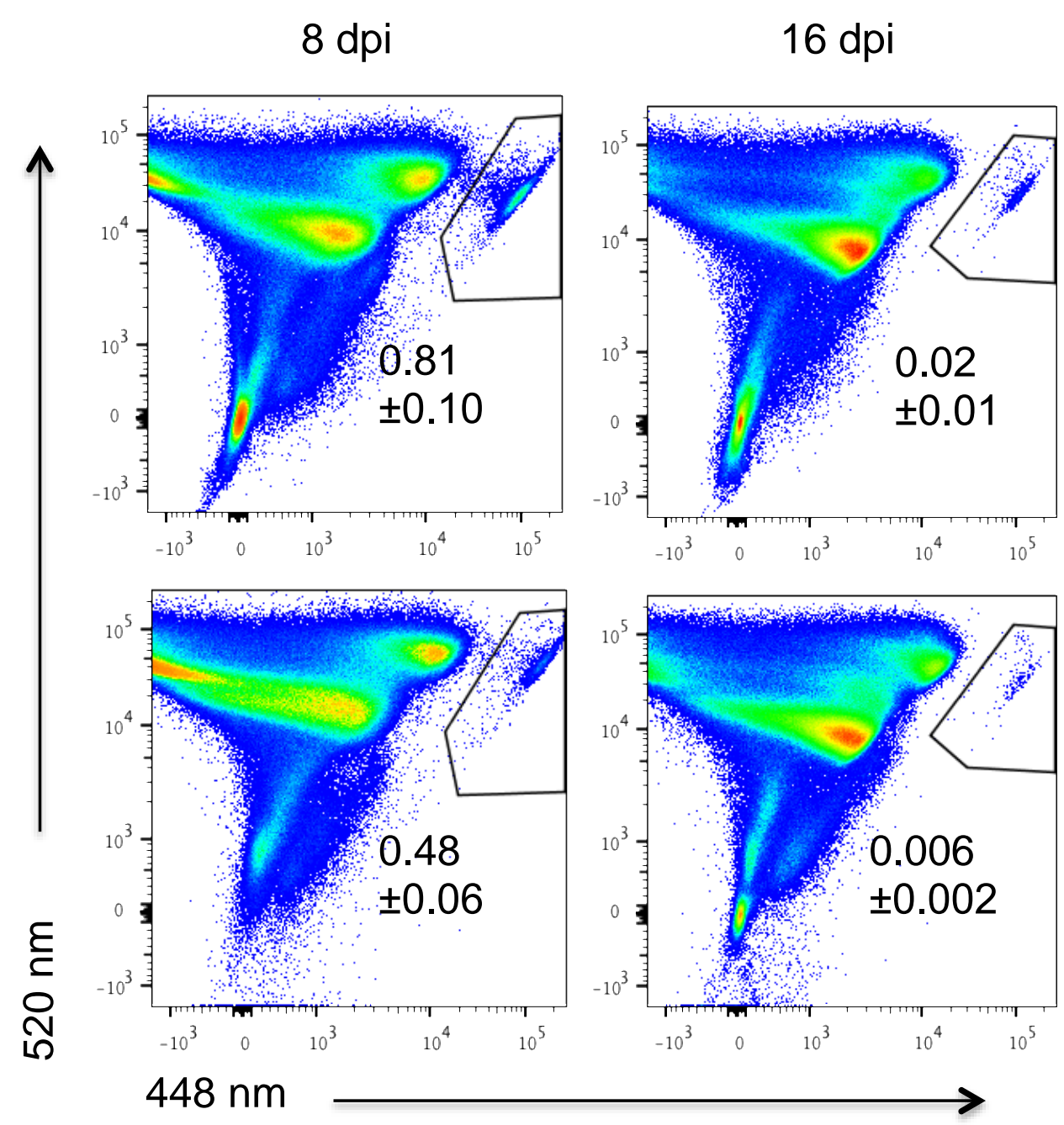

D.

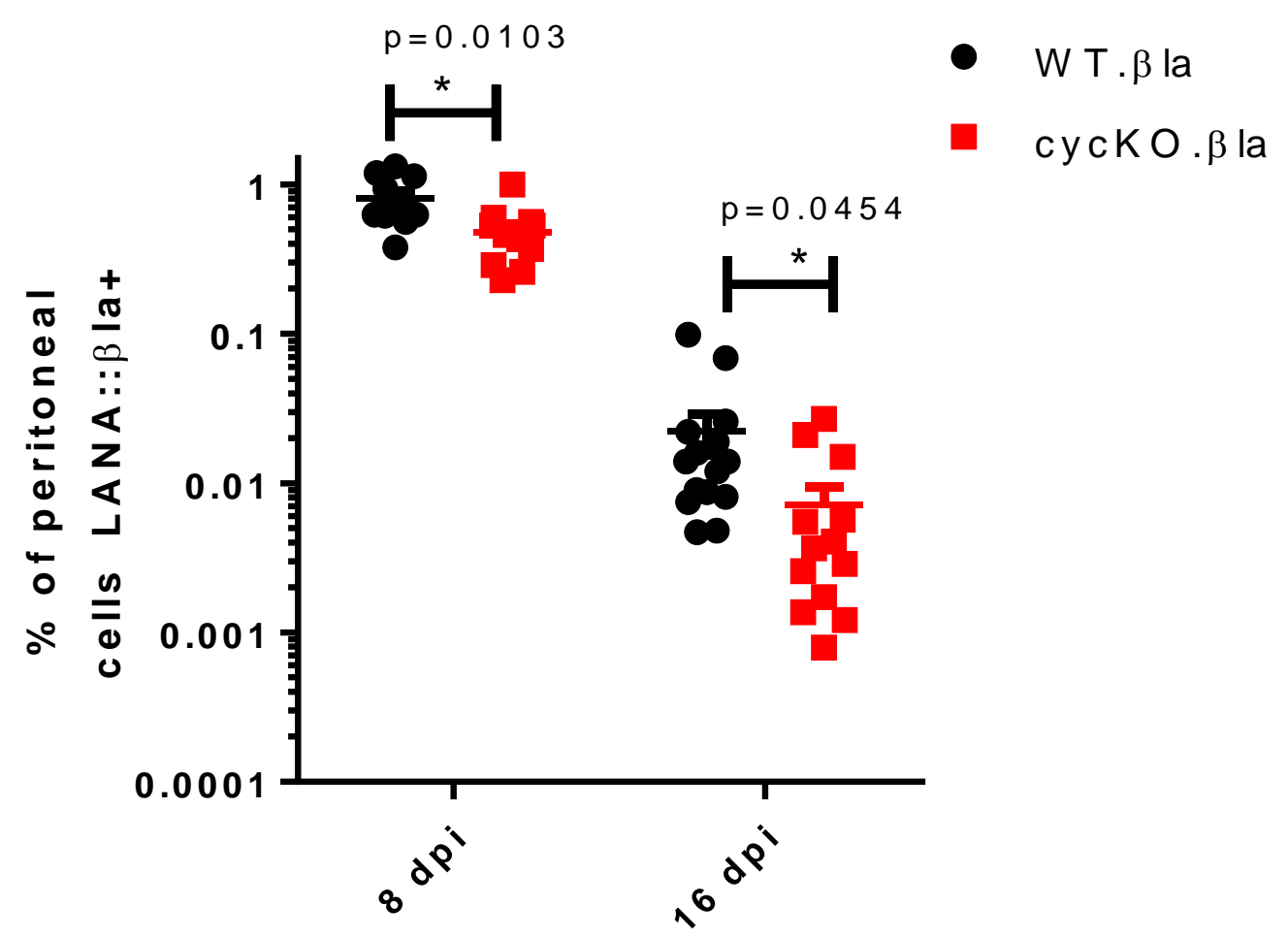


Figure 5: Disruption of the viral cyclin results in a reduced frequency of LANA::ßla expressing cells in the spleen of CD8-/- mice

A.

WT.ßla

Total cells
WT.ßla LANA::ßla+ cells
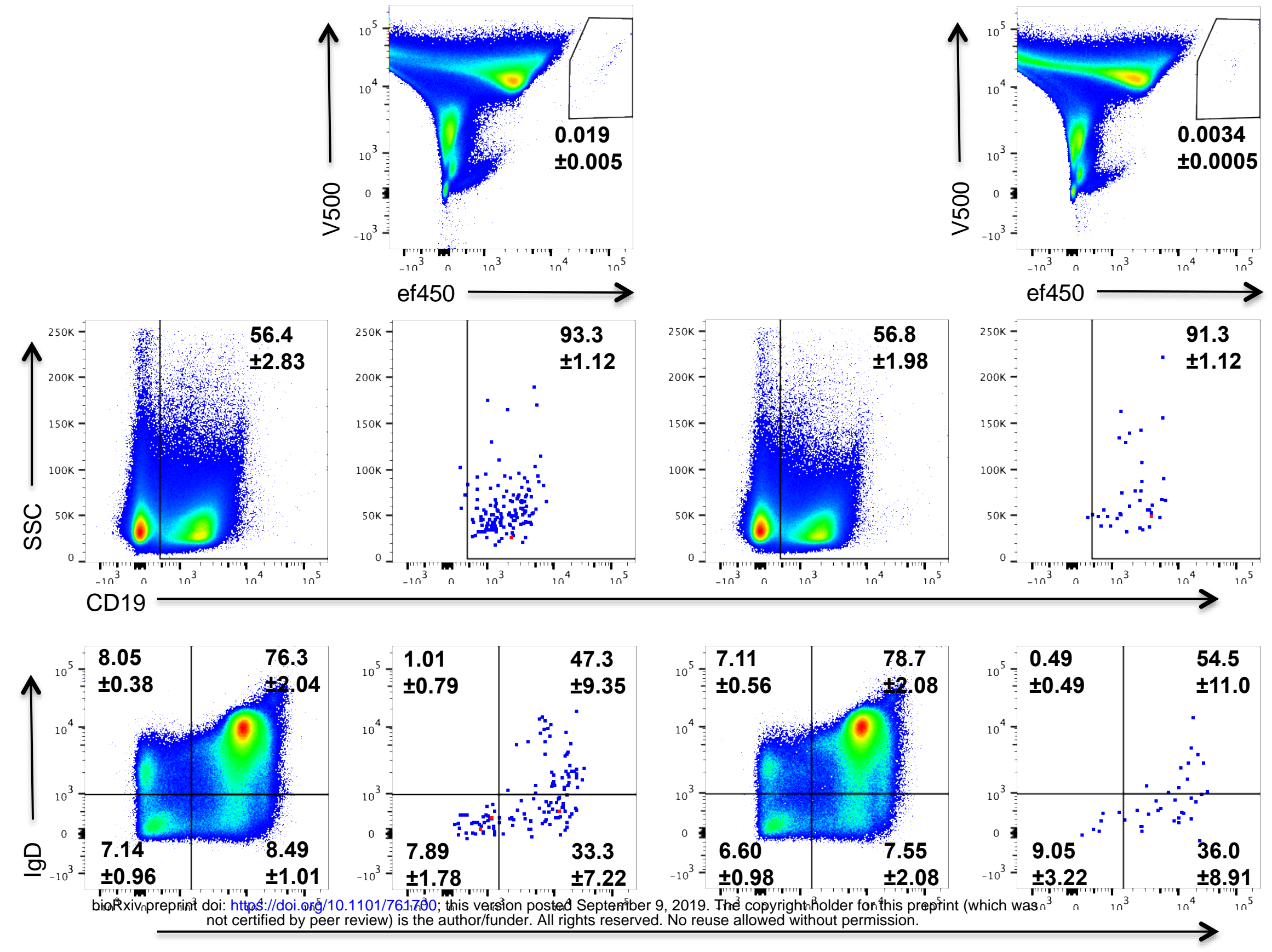

cycKO.ßla

Total cells

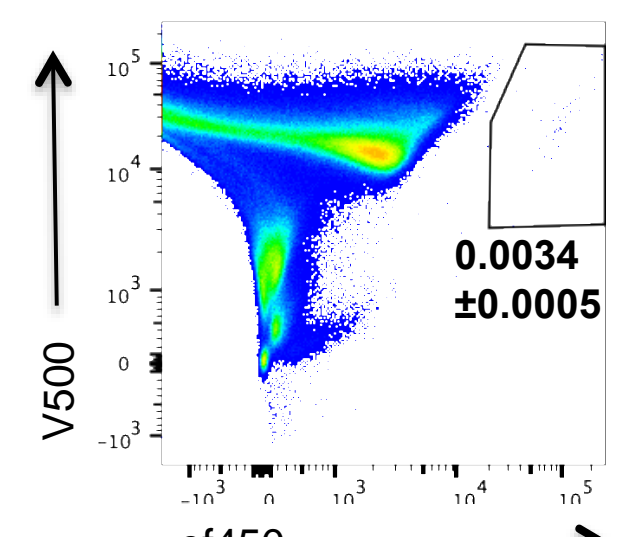

B.

cycKO.ßla
LANA::ßla+ cells
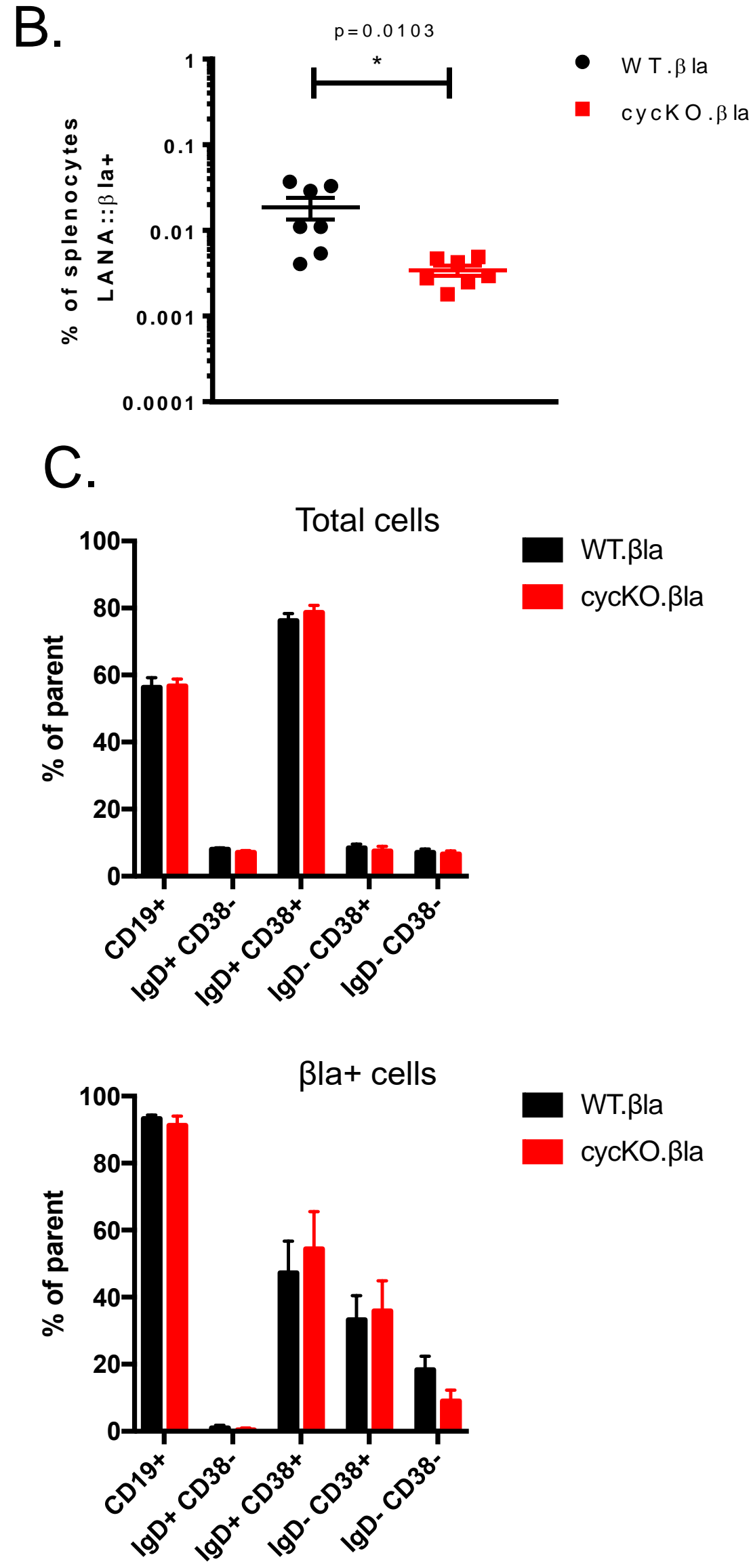

C.

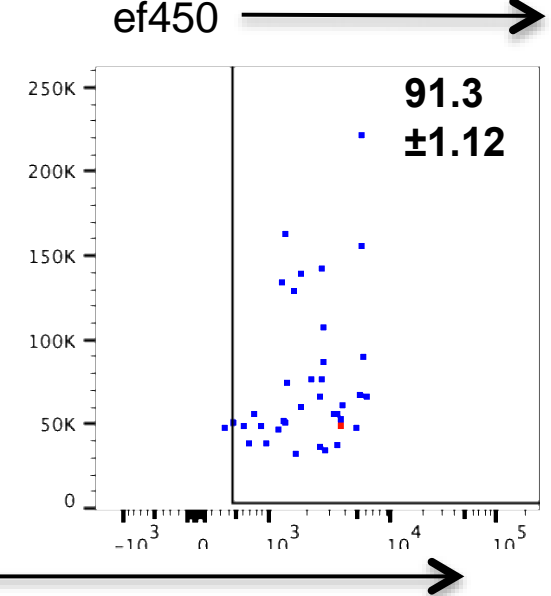


Figure 6: Disruption of the viral cyclin results in a reduced frequency of LANA:: $\beta$ la expressing cells in the peritoneum of CD8-/- mice.

A.

WT. Bla

Total cells
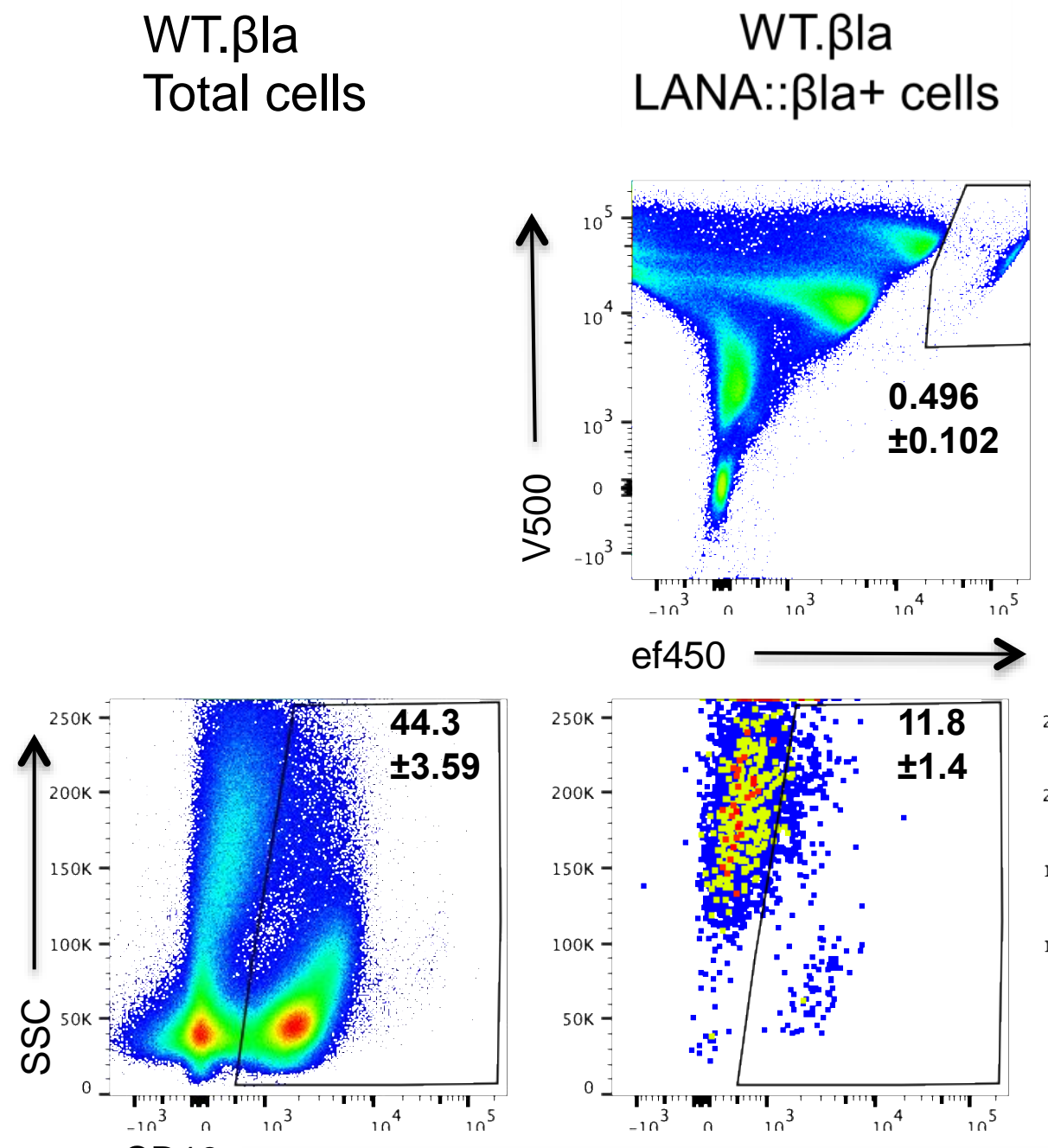

CD19
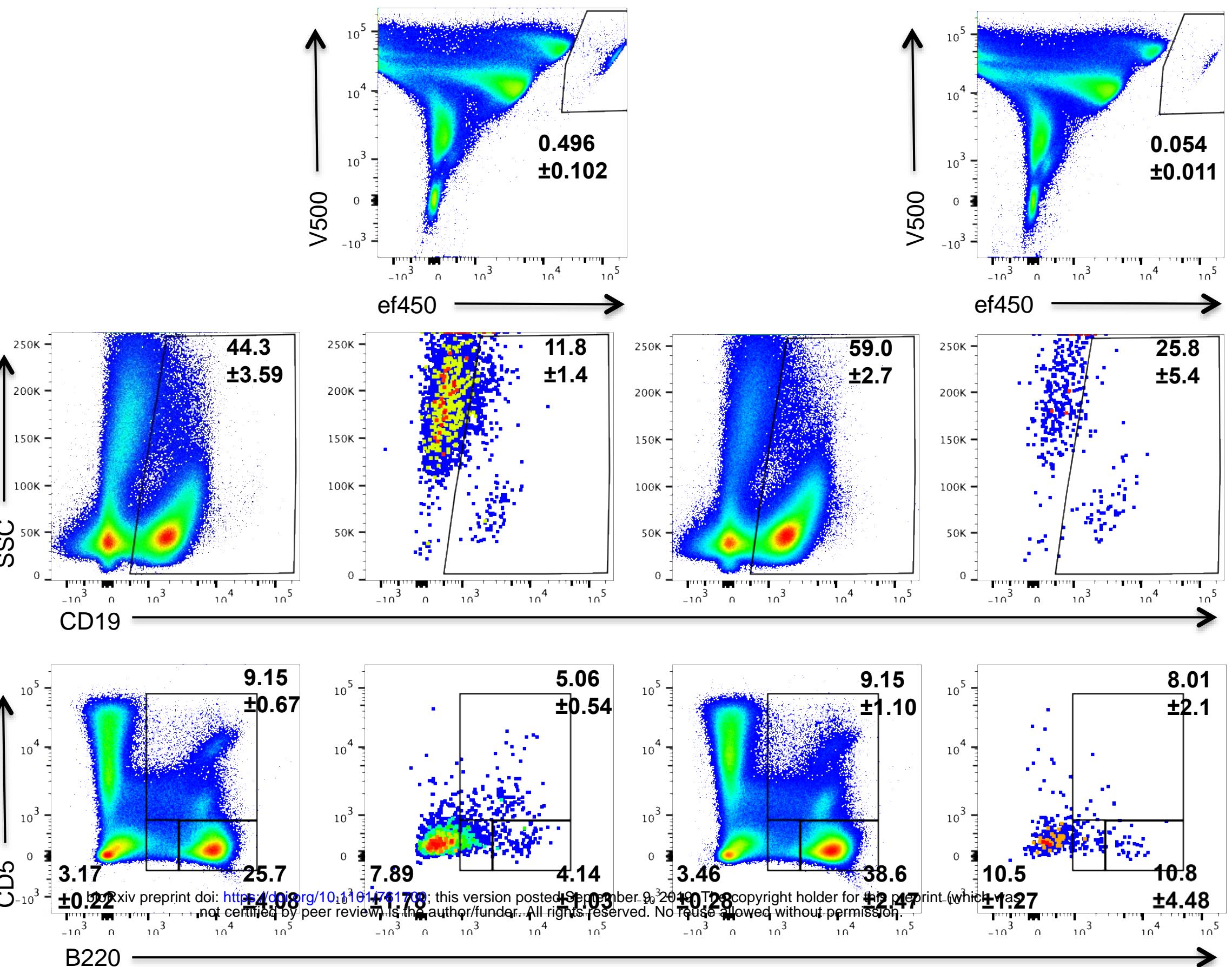

B.

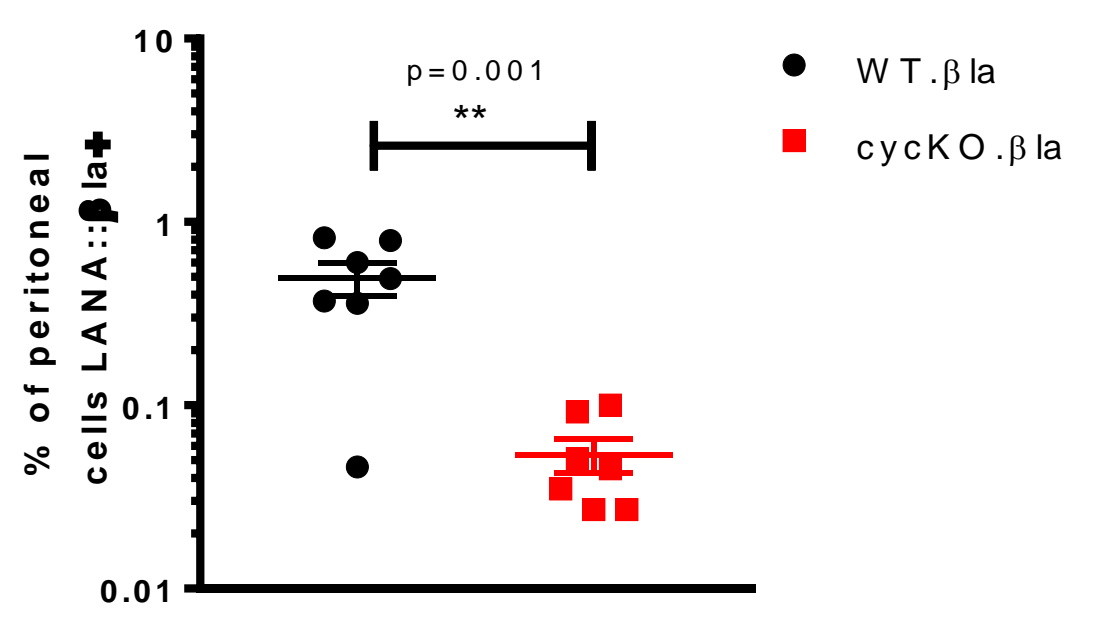

C.

Total cells

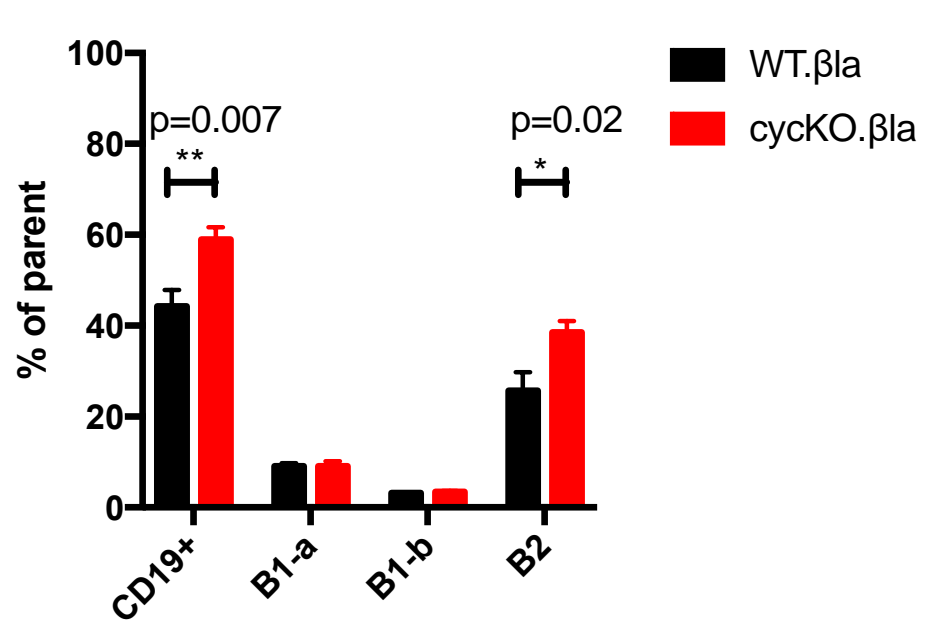

LANA::ßla+ cells

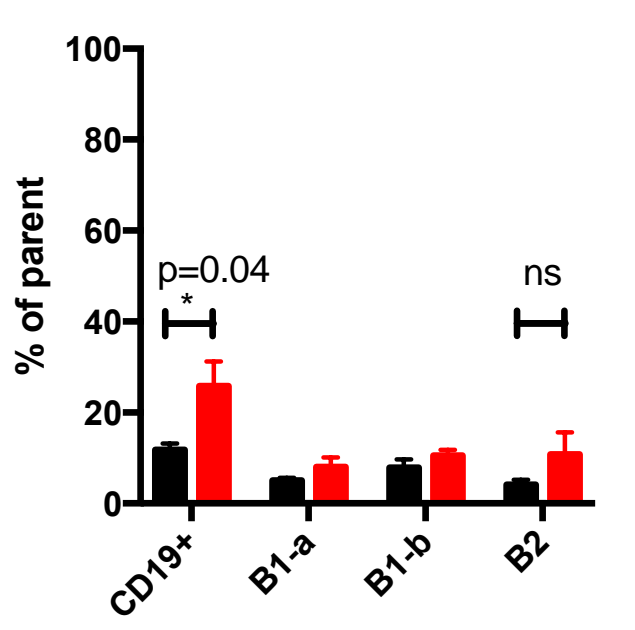

D. $\quad \beta$-lactamase

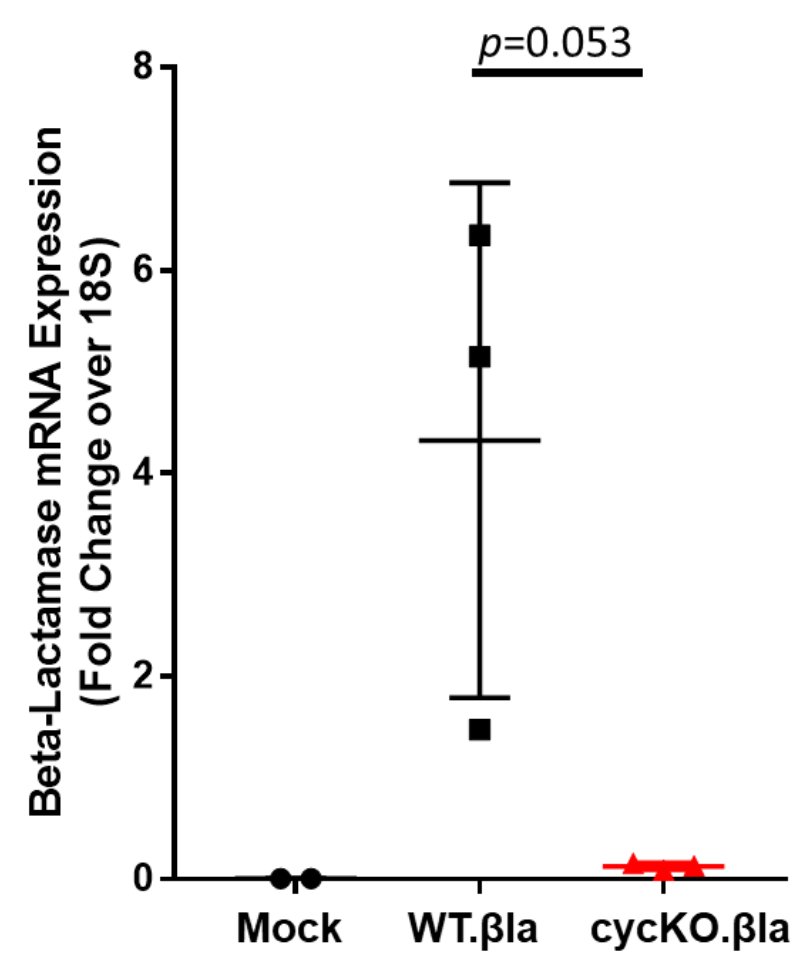

LANA

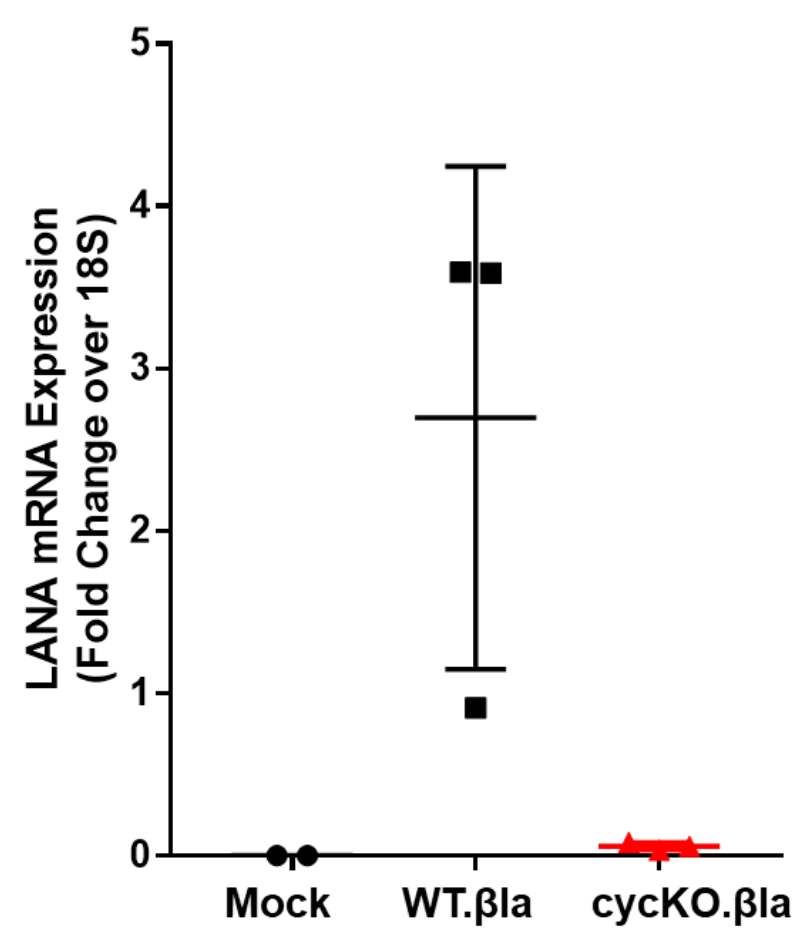


Figure 8 . The viral cyclin drives reactivation through increasing the pool of LANA expressing, reactivationcompetent, infected cells.

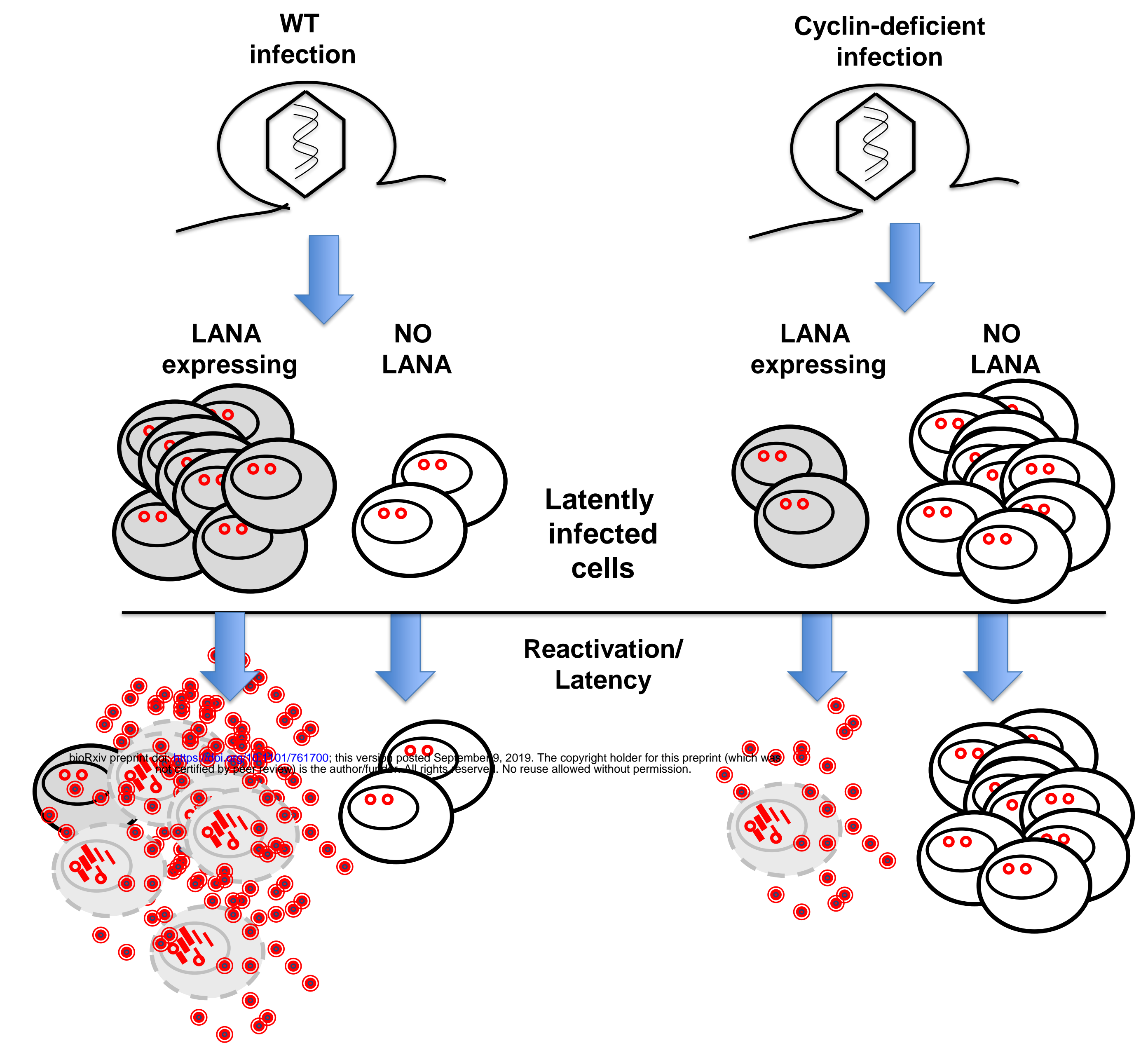

